\title{
Growth and Equity in Tertiary Education in Sub-Saharan Africa
}

\author{
Peter Darvas, Sonali Ballal, and Kebede Feda
}

\begin{abstract}
This study represents a first report of a regional cross-country analysis of patterns in equity and growth in tertiary education in Sub-Saharan Africa. In it, we analyse country-level surveys and regional statistics to see how expansion affected equity, how equity is explained by household characteristics and other factors, and what the intrinsic characteristics of the tertiary education system are that influence equity. Data show that in many instances, Sub-Saharan African countries fall behind other regions in terms of equity; and whereas some policies, such as diversification and more equitable pre-tertiary education can help, more efforts and more effective policies need to be introduced to make the system more equitable. The report argues that growth itself will not necessarily lead to improved equity and more equitable access to tertiary education can help the sector in achieving its higher-level objectives, including its contribution to competitiveness and prosperity.
\end{abstract}

Cette étude constitue le premier rapport d'une analyse de l'équité et de la croissance de l'enseignement supérieur en Afrique sub-saharienne. Nous analysons des enquêtes nationales et des statistiques régionales pour montrer la manière dont la croissance affecte l'équité, comment l'équité peut être expliquée par les caractéristiques des ménages ainsi que par d'autres facteurs et quels facteurs propres au système d'enseignement

AвOUt THE AUthors: All three authors work at the World Bank in Washington, D.C., but the study represents their views and conclusions, and do not necessarily represent official World Bank positions. PETER DARVAS is Senior Education Economist, SONALI BALLAL is Education Specialist-Consultant, and KEBEDE FEDA is Economist. ACKNOWLedgements: Some of the graphs and tables were completed by Michele Savini. Peter Materu provided continuous management support and oversight to this report. Valuable feedback and suggestions came from Andreas Blom, Emanuela Di Gropello, Himdat Iqbal Bayusuf, Kirsten Majgaard, Mamy Rakotomalala, and Mathieu Brossard. Burton Bollag provided editorial support. 
supérieur influencent l'équité. Les données montrent que, dans de nombreux cas, les pays d'Afrique sub-saharienne sont en retard par rapport à ceux d'autres régions en ce qui concerne l'équité. Tandis que certaines mesures politiques, comme diversifier l'enseignement supérieur ou rendre les enseignements primaire et secondaire plus équitables, peuvent aider, des efforts plus importants et des mesures politiques plus efficaces doivent être mis en place pour rendre le système plus équitable. Ce rapport soutient que la croissance ne conduira pas forcément à l'amélioration de l'équité et qu'un accès plus équitable à l'enseignement supérieur peut aider le secteur à atteindre ses objectifs les plus ambitieux, notamment contribuer à la compétitivité et la prospérité du pays et de la région.

\section{Global Trends in Access and Equity in Tertiary Education}

Tertiary education plays an important role in stimulating social and economic progress - a view that has a global consensus-along with its corollary: Prosperity is increasingly based on knowledge production, adaptation, and dissemination. Investing in tertiary education and research is a critical component of such knowledge production. Tertiary education ${ }^{\mathrm{I}}$ also contributes to poverty alleviation through boosting economic growth, improving the quality of services (including basic education and health), and helping to decrease disparities in accessing them. Other public benefits include higher productivity, technological catch-up, advances towards more entrepreneurial and civic societies, improvements in citizens' health, reduced population growth, and strengthened governance. Private benefits of tertiary education include better employment prospects, higher salaries, greater ability to save and invest, better health, wiser decision-making, and improved quality of life.

Tertiary education has been transformed from a system serving a select "elite" to one serving a massive segment of young adultsachieving access for the majority of this population in most developed economies and in a large number of lower-middle-income economies. There is no clear consensus about the minimum level of access to achieve parity with global education; but in our judgment, in most countries with the ambition of being competitive globally, at least a quarter of the citizens between ages I 8 and 22 must have access to some type of tertiary education. This expansion of access has typically happened in parallel with economic growth-contributing to the consensus that

1. For the purposes of this report, "tertiary education" includes not only the usual four-year university programme, but also two-year certification programmes, technical and vocational education and training, and any diploma/certificate programmes that require a secondary education certificate for entry. human capital accumulation through tertiary growth is a foundation of growth. Admittedly, the evidence for this relationship is anecdotal rather than statistically determined, as different countries present distinct cases and stories. However, economic growth unquestionably creates the fiscal space needed for the expansion. Pre-tertiary expansion also creates a demand for increased access to tertiary education.

In addition to expansion, tertiary education has become diverse in terms of affordability (including alternative sources of funding), disciplines offered, and types of colleges, ranging from research universities to liberal arts institutions, and from community colleges to academies providing professional education. As a result, the clientele has also changed as students from diverse backgrounds access tertiary education with a diverse set of job expectations, gaining a broader range of skills demanded by a variety of employers. The expansion combined with this diversification has led to a much more inclusive system, more heterogeneity, less elitism, and arguably more equity. Tertiary institutions have also changed their strategies from picking and choosing the best students to attend their academic "ivory towers" towards a greater focus on service-not only serving the needs of the students but also meeting the needs of the local national economies and public services. This responsiveness has also led to an ability and readiness to adapt to changing demands.

The importance of tertiary education for economic and social development in Sub-Saharan Africa is well established, including its links with poverty reduction and economic growth. Among other factors, tertiary education is also seen as helping countries to improve their capacity to absorb external aid (Walenkamp \& Boeren, 2007). In the absence of a robust and competitive private enterprise, effective tertiary education in developing countries may even be more critical in increasing technological capacity, enhancing skills, and advancing entrepreneurship. Tertiary education is also associated with lower levels of unemployment or under-employment, crime, and poverty, but also with greater civic participation and a well-informed electorate (Bloom, Canning, \& Chang, 2005; World Bank, 2002). The recognition of these benefits has increased gradually, and support to tertiary education by some governments and development agencies, including the World Bank, appears to have been increasing steadily. Yet in the majority of countries in Africa, the link between higher education, development, and poverty reduction still requires more attention (Bloom, Canning, \& Chang, 2005).

The starting point of our analysis is the confirmation that tertiary education is a crucial opportunity for the Sub-Saharan Africa countries to fulfill their strategic goals in developing competitive economies and 
stable democracies in their fight to eliminate poverty and increase prosperity. But to fulfill these expectations, public policy needs to address some persistent bottlenecks, including inequities in accessing, delivering, and benefiting from tertiary education. We intend to demonstrate that serving a limited group of clientele through a narrow channelwith a limited range of programmes-will not lead to sustainable growth of tertiary education sufficiently quickly to allow Sub-Saharan Africa countries to become not only inclusive but also globally competitive through investment in human capital.

In the past I5 years, the tertiary systems in the countries of SubSaharan Africa have significantly expanded their numbers of students. But reaching the milestone of mass higher education systems-even in numbers alone-seems to be decades away for the region. Also, while there have been some changes in certain countries and institutions towards diversification and developing a service focus, we argue that some elite characteristics remain in place that constrain the structural evolution of tertiary systems. A key factor in this context is the persistent inequity in access. Unless that inequity is addressed, elitism will continue, creating obstacles to fulfilling the promise of tertiary education-that of creating a competitive society which also offers better opportunities to all so that a solid middle class may emerge.

\section{Equity}

Equity, derived from social justice principles, is the concept of treating everyone with fairness, if not necessarily equality. Key steps in formulating policies for ensuring equity in education include: (a) determining the access opportunities for different groups based on traits that are unalterable at the time of access such as gender, location, ethnicity, or socio-economic status (SES); (b) determining the adequate amount of resources required for each group to achieve equal access opportunities and (c) addressing the concept of absolute deprivation, with the understanding that "societies may decide to intervene to protect the livelihoods of its neediest members ... . even if the equal opportunity principle has been upheld" (World Bank, 2005, p. I9). Equity should be complemented by policies aimed at enhancing the quality, efficiency, and accountability of tertiary institutions and the education they provide. While we consider this relatively broad meaning of equity, in the context of this analysis, we use mostly data on tertiary education attendance and completion, analysing equity in terms of disparities in attendance and completion by income, gender, location, and other factors.

An equitable approach leads to a tertiary system that is more open and diverse, both in its students and in the types of instruction/pro- grammes it offers. In turn, this system contributes to cohesion and poverty reduction at the same time that it expands its functionality and becomes accountable to a wider public. A more closed system implies a higher education structure that is still a stronghold of the elite and that provides little in the way of social change and public benefits. However, measurement of equity is a challenge given the data issues and the limited scope of tertiary education. The limited scope, coupled with a low gross enrolment rate (GER), implies that the system is almost by default skewed against disadvantaged (mostly low-income) students. This result is largely due to the scarcity of high quality and effective education at the pre-tertiary levels from basic to upper secondary. If there has been growth only in tertiary education enrolment, but not in equity, then large swaths of the population are excluded from participation in-and benefit from-economic growth. In this scenario, inequity is a constraint, and tertiary education does not fulfill its potential as a driver of development. Inequitable access leads to a system where the benefits of tertiary education are primarily private.

Why is it important for governments and policymakers in Sub-Saharan Africa to address the persistent inequities in tertiary education? The compelling reasons are social, economic, and systemic. Tertiary education occupies an important place in public policy debates. These debates typically focus on the economic importance of the sector, the significance of investments, the role of public financing in tertiary education, and the need to find a better balance between tertiary and other levels of education in governments' strategic priorities. Yet the public debates about tertiary education typically focus on the sector's fast growth while ignoring the risks that these persistent inequities pose to the role of tertiary education as a key support to the development agenda.

More equitable access and tertiary education services can help the sector to achieve its higher-level objectives, including its contribution to competitiveness and prosperity. If access is opened up more broadly to well-performing but poor students, tertiary education can grow faster. If funding is divided with a better balance between indirect, tax-based financing and direct, fee-based financing, growth may be better sustained over time. Fairer distribution of costs can also assist students coming from lower-income families in mitigating high opportunity costs - that is, the costs of not earning income while staying in education for additional years. The efficiency argument must also be considered, as countries in Sub-Saharan Africa may lose opportunities in their effort to accumulate human capital if some of the more talented and better performing students are lost because they cannot afford access and drop out of education before acquiring higher skills. Arguably, more diverse 
student populations and more diverse tertiary services can also expand the public benefits as students from more financially constrained backgrounds are more likely to engage in various public services, such as teaching, nursing, or community-based services requiring higher skills. Consequently, our report looks beyond the important but not exclusive fairness argument. We argue that tertiary education's strategic role and its strategic agenda become more realistic if access is more equitable and illustrate this argument with detailed data analyses.

\section{Data Sources}

The availability of reliable data on tertiary education in Sub-Saharan Africa is limited. This factor constrains not only analysis but also policymaking and public debates. Our report highlight some trends that may be alarming; but beyond these trends, we also argue that governments, policymakers, and leaders of tertiary institutions should pay more attention to collecting and monitoring data-not just in terms of the number of indicators or countries they track, but also in the implications of these data. In the absence of adequate monitoring, public debates remain limited and discourse superficial. Although such debates continue to reinforce the general importance of the tertiary sector, they will also leave unaddressed other, perhaps more important, issues such as fairness, openness, efficiency, sustainability, and value for money.

A lack of adequate statistics poses problems in terms of carrying out analyses, drawing conclusions, testing assumptions, and measuring policy effectiveness. In particular, reliable information is lacking about the composition of the student bodies in terms of gender, socioeconomic status, and geographical origin. Information about student type-full-time, part-time, short-cycle, long-cycle, and majors-is also scanty. Other areas demanding deeper research are how students advance through their education, quality of outcomes, inputs, unit costs per student, unit costs per graduate, expenditure patterns and size, use of non-governmental revenues, and the equity of outcomes as measured by jobs and earnings, as well as other associated and monitored externalities. In short, we need to know more-both in general and in specific terms-about how, exactly, tertiary education serves broader social and economic goals. These are critical issues as Sub-Saharan Africa and other low-income countries face competing social interests that must be addressed with persistently limited public resources.

Our unit of analysis is the country systems and country-level data. We look at country systems and country-level data disaggregated mostly by gender and by income and, when possible, by other factors including location and ethnicity. Further, we use available administrative data about the institutions, enrolments by ownership, types of programmes (using the International Standard Classification of Education [ISCED]), fields of studies, and aggregate costs. The latter factor also provides information about unit costs. The report uses several different sources of data including the UNESCO Institute for Statistics (UIS), the World Bank Education Statistics (EdStats) database, World Bank reports (country status reports, education sector studies), and other analytical work. The primary sources of cross-country analysis within the Sub-Saharan Africa region are various household surveys. Though useful, the formats of these household datasets required a fair amount of cleaning, analysing, and standardising across countries to produce comparable data. Using country-level data has both limitations and opportunities. The limits are in our ability to draw statistical inferences, given that countries are diverse in size and complexity. The opportunities are in the storylines of the country cases that we can explore. In the second phase of our analysis, we will explore key country cases in more depth and, at that point, will attempt to use more robust statistical methods drawing on student data to disclose the impact of tertiary policies on equity and growth.

In presenting this report, we are cognizant of the differences between administrative and survey data. The administrative data are reported by national governments to international agencies such as the UNESCO Institute for Statistics. The source of government data is generally country statistical reports, based on reporting by tertiary institutions or by annual student censuses. The household survey data come from surveys conducted by agencies that use statistical sampling to determine the population for the survey. The advantage of survey data is that it can be standardised across countries and can also be used to track indicators or cohorts of individuals over time, linking information about education attainment to external factors such as household data, consumption, poverty, and employment. On the other hand, questions where standardised surveys rarely venture and comparisons are difficult to make include typically how successful students are in their achievement, attendance, and completion; how funds, including public expenditures, are used; and how tertiary services are structured by ownership, quality, fields of studies, and types of degrees.

Therefore, in order to present the big picture and key social trends, our analysis predominantly relies on household data; in a later phase, for further policy analysis and recommendations, we will also combine the survey-based data with administrative reporting and official statistics. Figure i illustrates the differences between the two sources of data. Normally, the indicators for each country should revolve around the 
Figure 1. Higher education gross enrolment rate according to UIS and household survey estimations in the year of the surveys in 24 Sub-Saharan Africa countries.

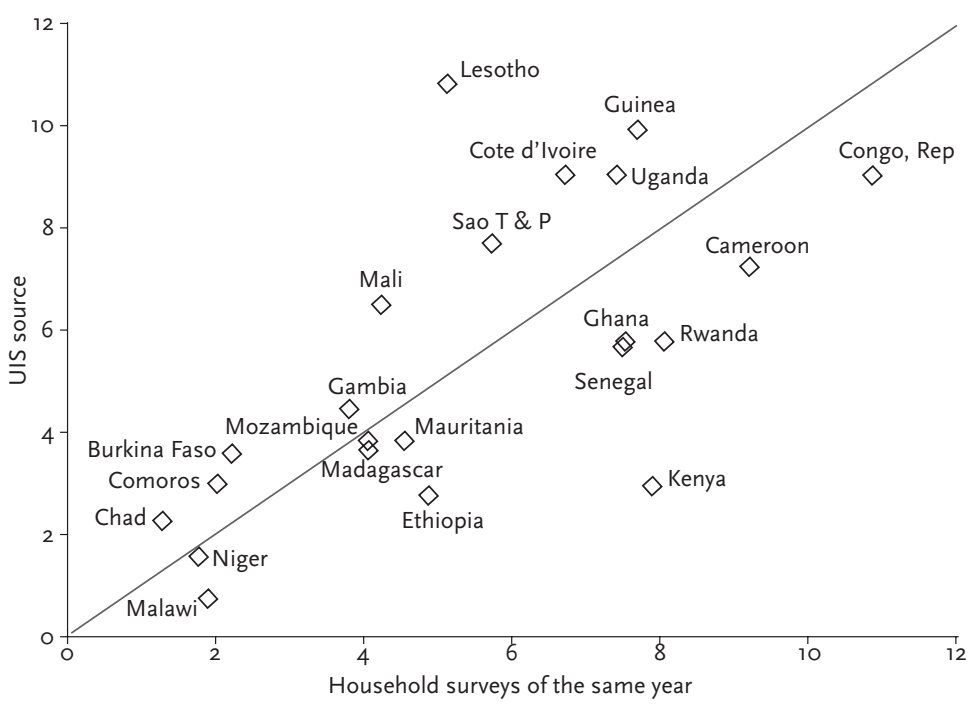

Source: Authors' calculations from household surveys and UIS (2010).

diagonal line; but in practice, few are even close to it. In slightly fewer than half of the countries, the GER reported to UIS is higher including in Lesotho where the survey measures GER at half of the official administrative number. Among the remaining countries, the survey data are higher, including cases such as Kenya where the survey-measured enrolment rate is more than twice the official GER.

We intend our analysis to contribute to the literature on equity in tertiary education by a strong reliance on household survey data and, especially in the second phase of our analysis, on combining household survey data with administrative numbers. With the household surveys as a source, Table I provides, for each Sub-Saharan Africa country, the gross enrolment rate for tertiary and secondary education, the gross enrolment rate for upper secondary and tertiary education for the highest income group, and the share of agricultural and wage employment. In addition, we use household survey data regarding location of students, parental education, and earnings while for others-including gender, structure of tertiary education programmes and services, and public expenditures, we use administrative numbers. In addition, we use the most recent available census data for Ghana (20I0) and refer to data used by other agencies and analysts.

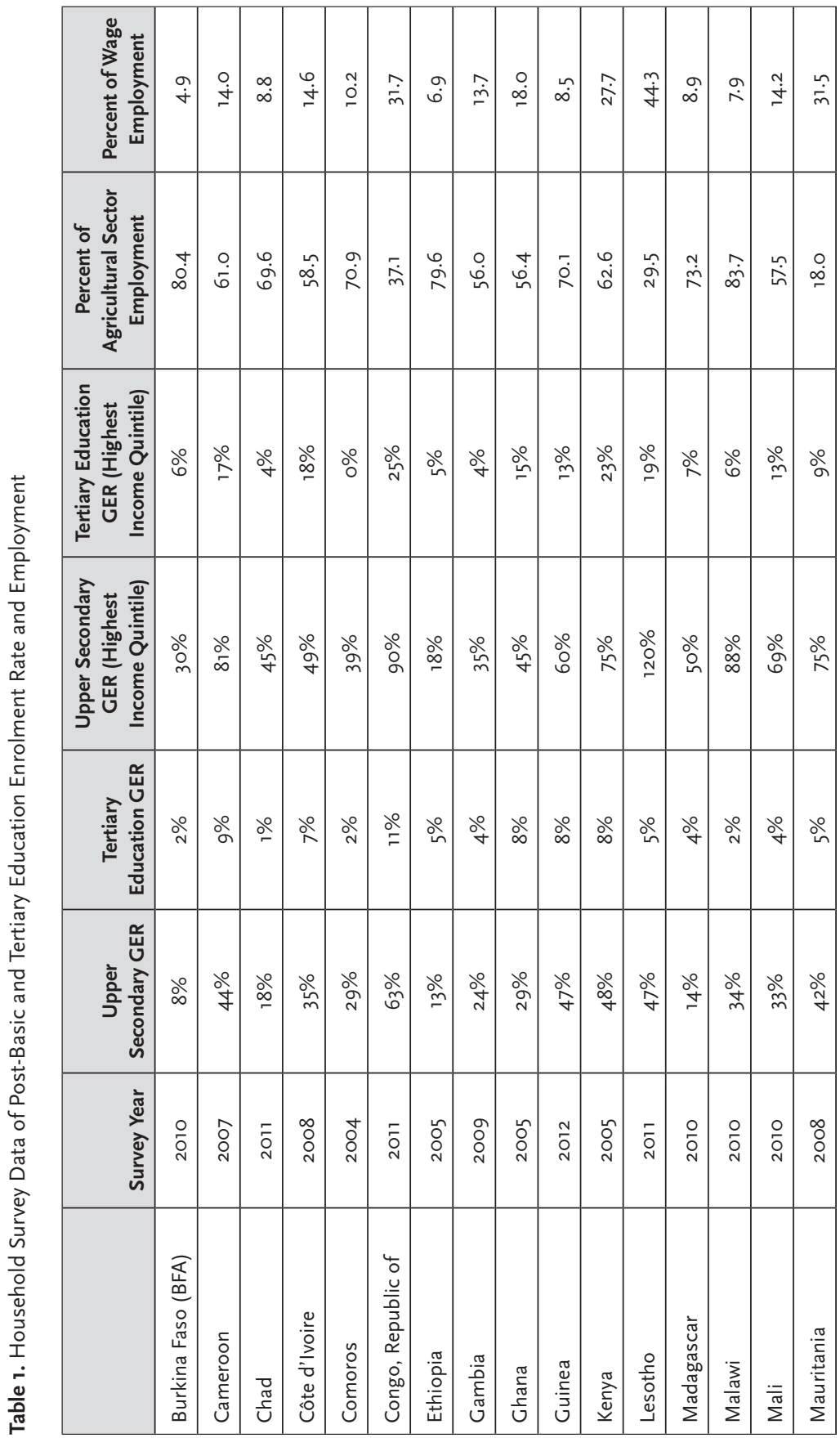




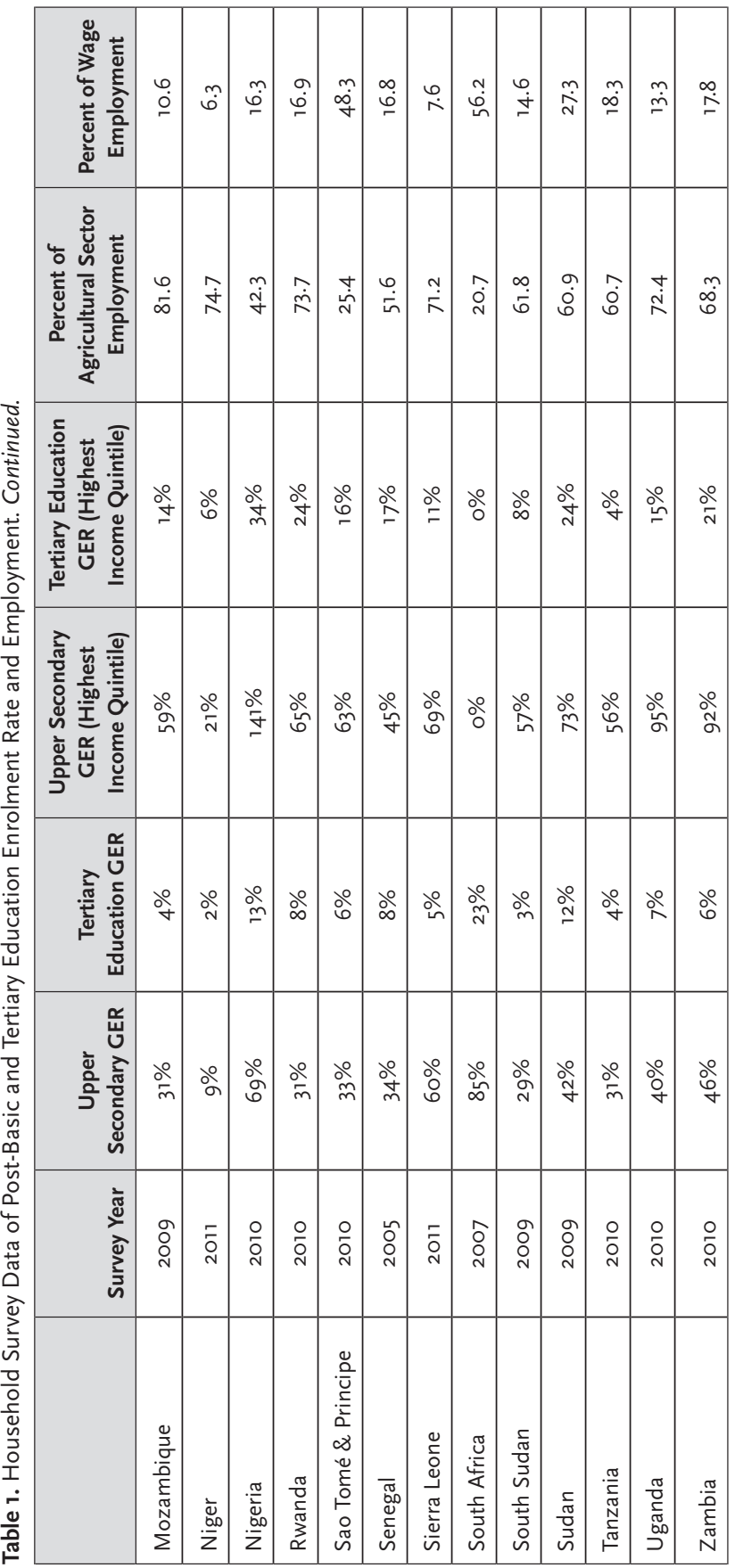

Figure 2. Long-term trends in tertiary education enrolment rates between 1970 and 2008

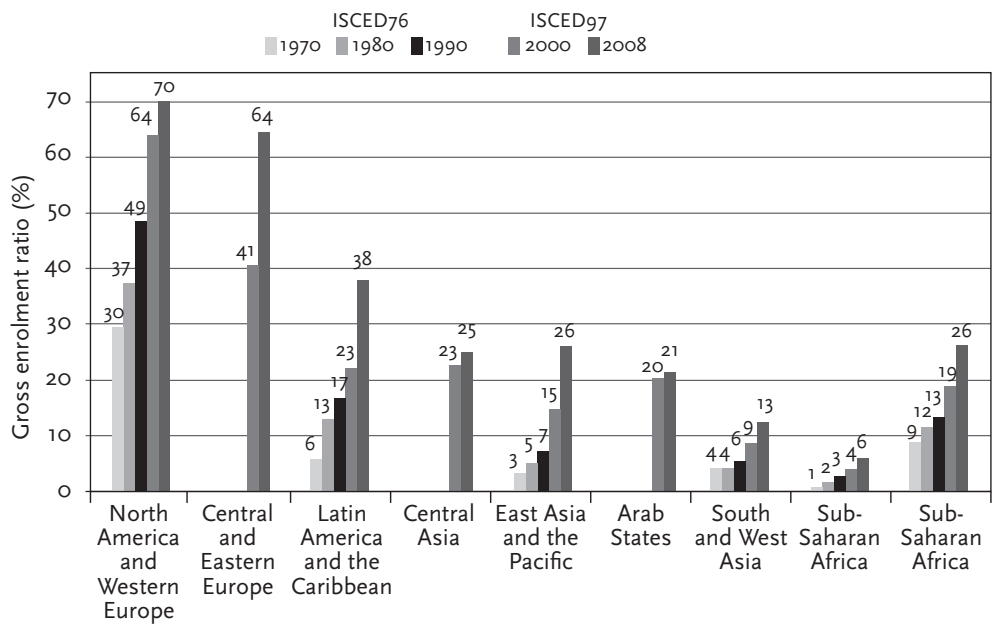

Source: UIS (2010)

\section{Tertiary Education and Economic Growth}

Sub-Saharan African countries' tertiary education systems are still far from being caught up with global trends. While there has been a rapid expansion in enrolments, population has grown much faster than the global average; and as a result, the enrolment rate has grown not much faster than the global trends. Long-term projections by UNESCO's UIS demonstrate, by using administrative data of enrolment rates, that the GER in Sub-Saharan Africa barely surpasses the global averages measured 40 years ago. Given these trends, Sub-Saharan Africa will not be able to catch up with the other regions in the foreseeable future. (See Figure 2.)

Over the past decade, tertiary education has grown across the world; the expansion has been higher in developing countries including SubSaharan Africa. In general, the greatest increases have been in regions that were on the lower levels of tertiary education enrolments. Between 2000 and 20I0, tertiary GER in Sub-Saharan Africa grew from 4\% to $7 \%$ at an annual average growth rate of $8 \%$. (See Figure 3.) Latin America and the Caribbean at 9\% and South Asia at 9\% were the only other regions with similar growth spurts. The fast increase in tertiary enrolments has been fuelled by increasing secondary school enrolment and graduation rates as well as by increases in the tertiary school-age population. Despite the surge in enrolment numbers, however, the 
Figure 3. Tertiary GER by region, 2000 and 2010.

60

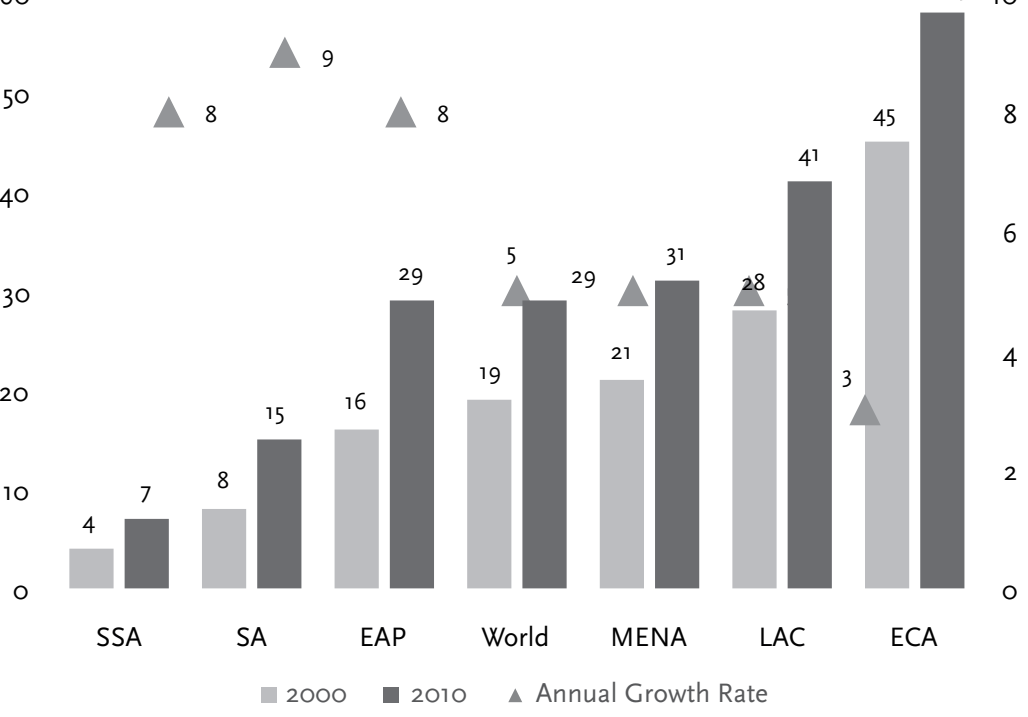

Source: EdStats (2013)

overall tertiary coverage in Sub-Saharan is only $7 \%$-extremely low, which lags far behind the rest of the world. It is almost three times less than the average tertiary enrolment rate for the world.

The relationship between economic growth and tertiary enrolment is significant and positive. Figure 4 illustrates the link between the gross domestic product (GDP) per capita of selected Sub-Saharan Africa countries and their corresponding tertiary education participation rates. Overall, the strength of the relationship and the slope is skewed by the large number of countries with low GDP and low GER. Figure 4 also suggests that each country represents a storyline; it is almost as if the trend is established from outliers and significant differences in terms of the relationship between economic wealth and tertiary expansion. Among the lower-middle-income countries, Nigeria, Sudan, and Cameroon appear to have relatively high tertiary GERs; Senegal and Zambia, Lesotho, Sao Tomé and Principe and, surprisingly, Ghana have lower enrolment rates relative to the national income. Among the low-income countries, Uganda, Togo, and Rwanda have a relatively high tertiary GER, whereas household data show very low enrolment rates in Malawi and Niger. Some Sub-Saharan Africa
Figure 4. GDP per capita and higher education GER

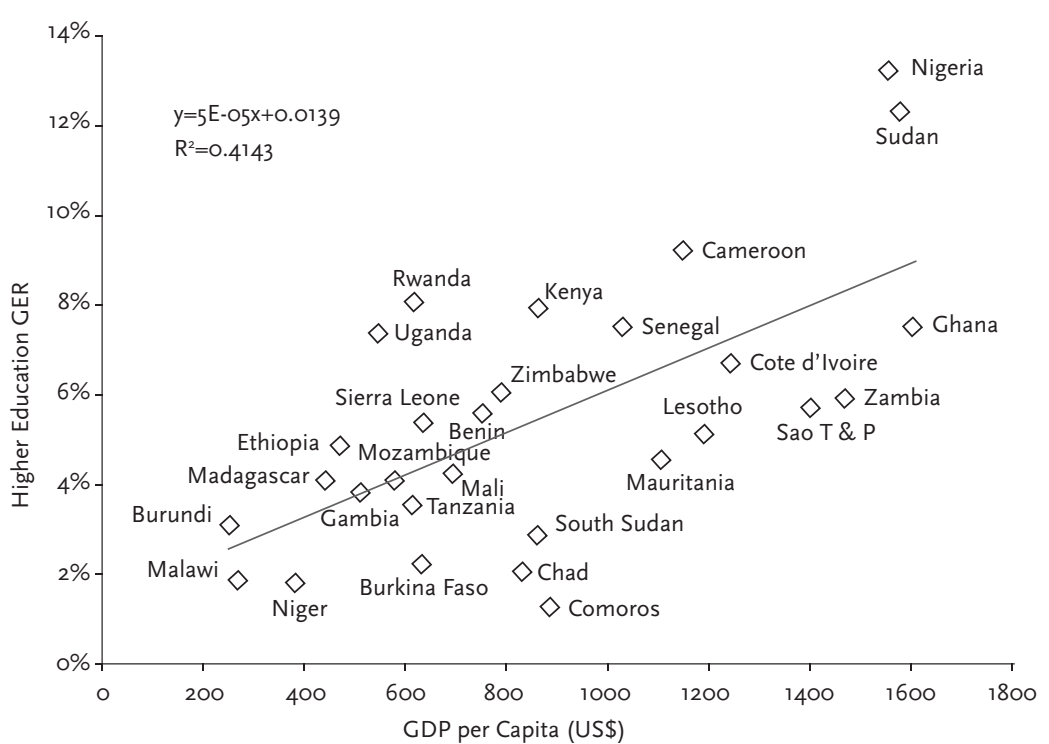

Source: Authors' calculations based on household surveys.

Note: Four Sub-Saharan African countries (Republic of Congo, Namibia, South Africa, and Gabon) with GDP/capita > 600 or GER above $15 \%$ are outliers for the distribution and are not presented in the figure, but the fitted line takes their positions into account.

countries possessing oil and other rich natural resources have relatively high GDPs but lack economic diversity and lack of robust access to tertiary education.

The differences in tertiary education participation rates between Sub-Saharan Africa and other countries or regions is due to a combination of social, economic, and structural reasons and not just to the country's standing on the global wealth index. Countries in Sub-Saharan Africa have much lower participation rates in tertiary education when compared to countries from similar income or economic backgrounds. For example, Figure 5 illustrates differences in enrolment among four Sub-Saharan African countries (Tanzania, Burkino Faso, Kenya, and Senegal) and four Asian countries with low or lowermiddle incomes (Bangladesh, Cambodia, India, and the Philippines). In all four Asian countries, the enrolment rate in tertiary education is high irrespective of their wealth, whereas in Sub-Saharan Africa, enrolment rates are low in all the selected countries without regard to the GDP/capita. 
Figure 5. GDP/capita and tertiary GER for selected Sub-Saharan Africa and Asian countries.

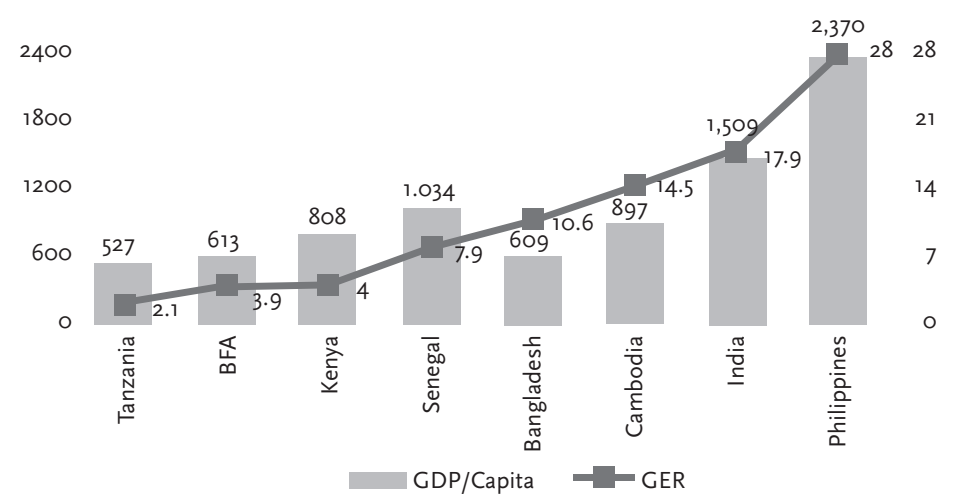

Source: EdStats (2013).

Note: Since GER data for the non-Sub-Saharan Africa countries was available only from EdStats/UIS, we took the GER for Sub-Saharan Africa countries from EdStats for this graph only for comparison purposes.

Figure 6. Share of agriculture employment and tertiary GER.

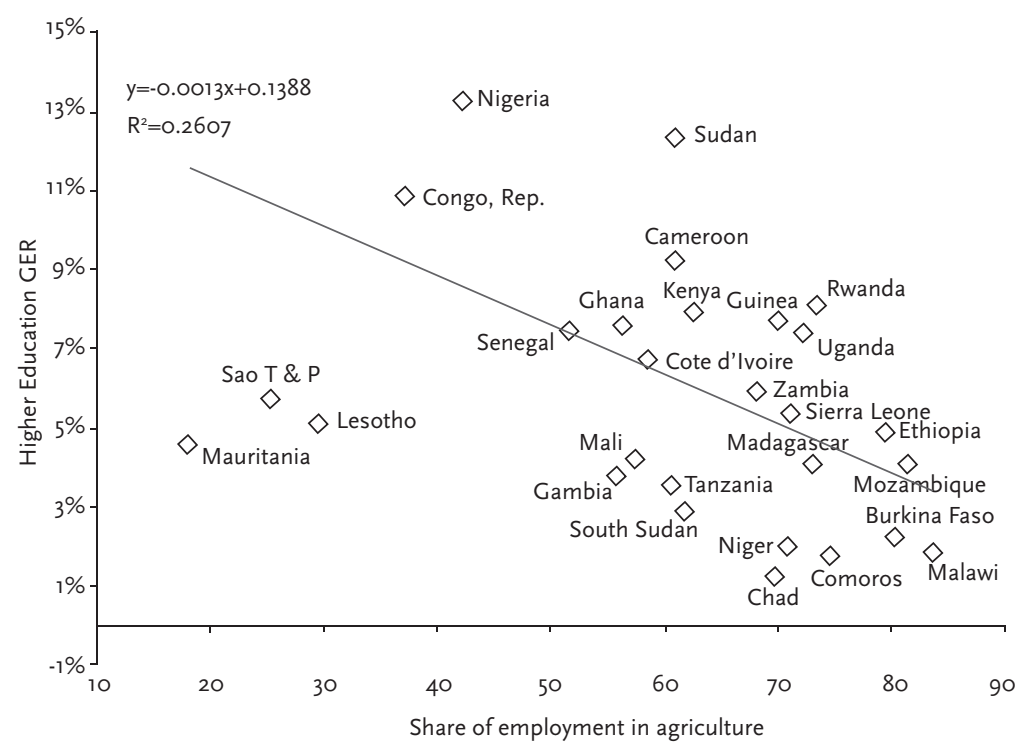

Source: Authors' calculations based on household surveys.
Figure 7. Economic structure by industry of employment and GER.

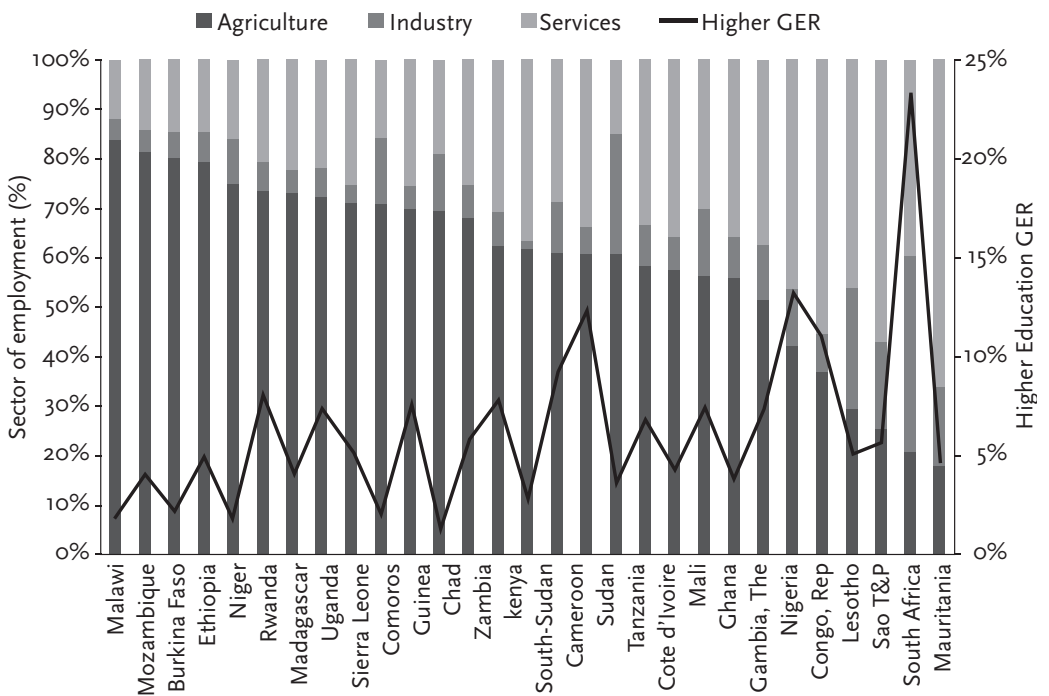

Source: Authors' calculations using household surveys.

Note: The GER we use is unadjusted to maintain comparison with the GER data for employment.

Our findings demonstrate stronger and clearer trends in terms of the relationship between the countries' economic structure and their tertiary enrolment. Agriculture continues to be the largest employer in Sub-Saharan Africa; its share ranges from more than $80 \%$ in Malawi to approximate $60 \%$ in Senegal. (See Figure 6.) Clearly, the more countries move away from agriculture as the dominant employer, the greater the demand for tertiary education.

Understandably, the non-agriculture sectors-manufacturing and services-are closely associated with growth in tertiary education. In general, services seem to have taken a significant part of employment, while employment in industry/manufacturing remains constrained in most countries with some exceptions (Tanzania, Lesotho, South Africa, and Sao Tomé and Principe). The country cases here show some more significant variations. Nigeria, Cameroon, Sudan, and Rwanda show a high GER despite having a large percentage of the workforce employed in agriculture, while Mauritania, Lesotho, Sao Tomé and Principe have lower GERs despite a very low share of agriculture-related employment. (See Figure 7.) 
Figure 8. Upper secondary GER and tertiary GER.

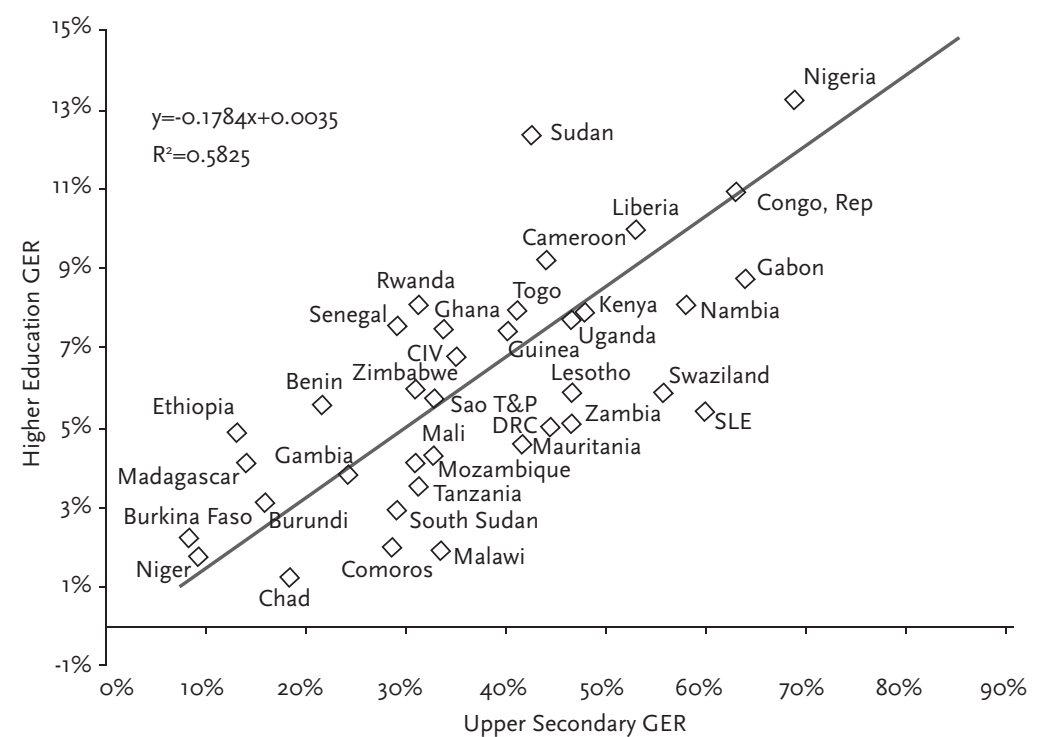

Source: Authors' calculations using household surveys.

The relationship is strong between tertiary and pre-tertiary enrolment and growth. (See Figure 8.) At the same time, Sub-Saharan Africa countries exhibit interesting variations in the extent to which pre-tertiary education growth explains tertiary education growth. The relationship seems to be stronger among Francophone than Anglophone countries. (See Figure 9.) Different regulations and policies guiding the transition are behind these differences. In Francophone countries, the successful passing of the baccalaureate exam automatically leads to tertiary-level admission. These structural differences also lead to variations in subsidies, benefit incidence, and, as we discuss below, differences in equity patterns.

\section{Tertiary Education Growth and Equity}

Expansion in tertiary enrolment has not resulted in improved equity; most of the increases were limited to the highest income groups. While the gains in access for the middle-income groups have been limited, the poorest section of society has practically no access to tertiary education in most African countries. The Sub-Saharan Africa region is
Figure 9. Upper secondary and tertiary education GER among Francophone and Anglophone countries.
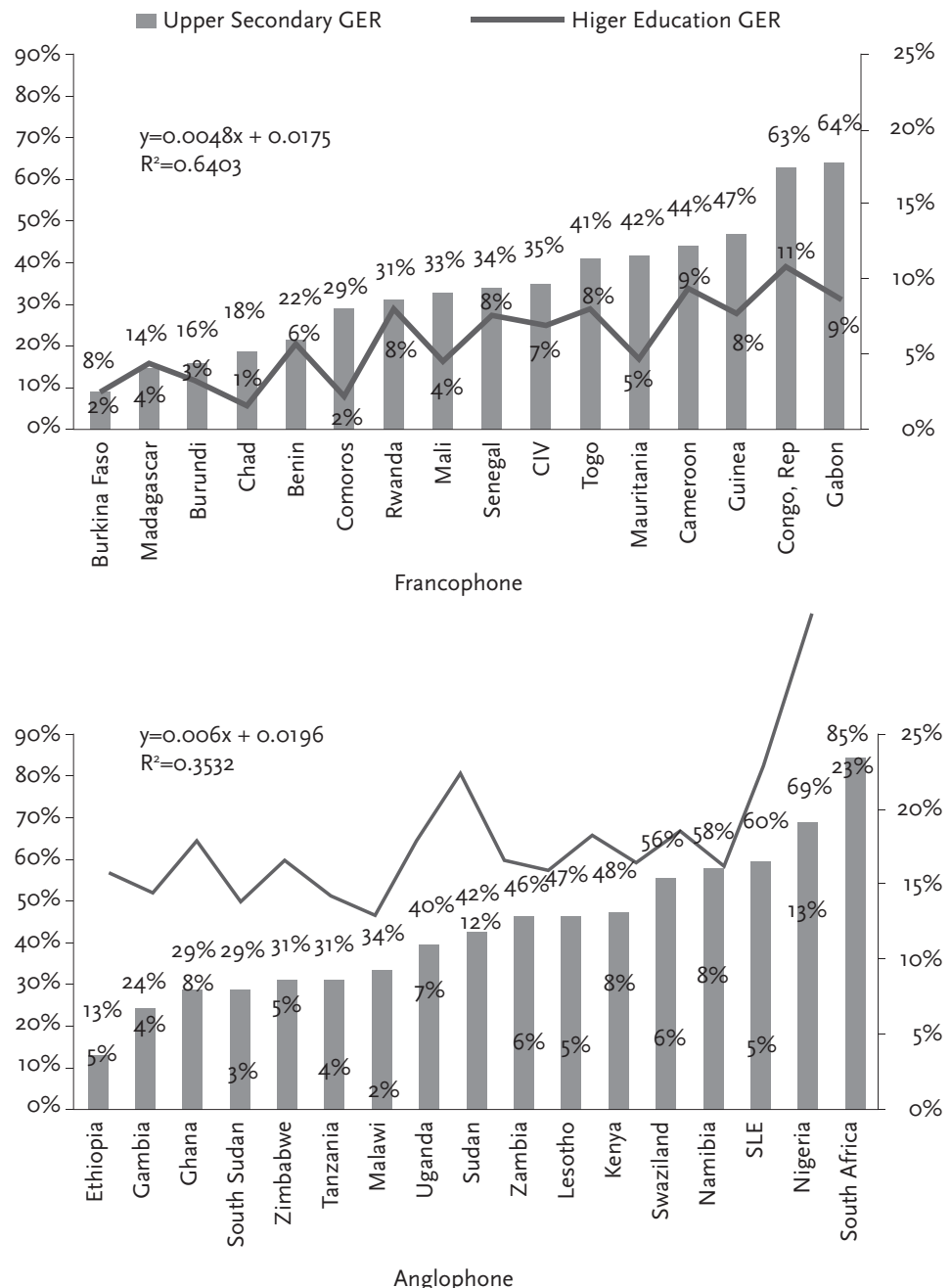

also unique in that access for women is not catching up with access for men. Most tertiary education systems remain elitist with the bulk of enrolments being limited to students who are high-income, male, urban, members in the majority ethnic group, and and/or those with parents (particularly the father) who are well educated. 
Figure 10. Percent of tertiary enrolment (18-29-year-olds) by wealth quintile.

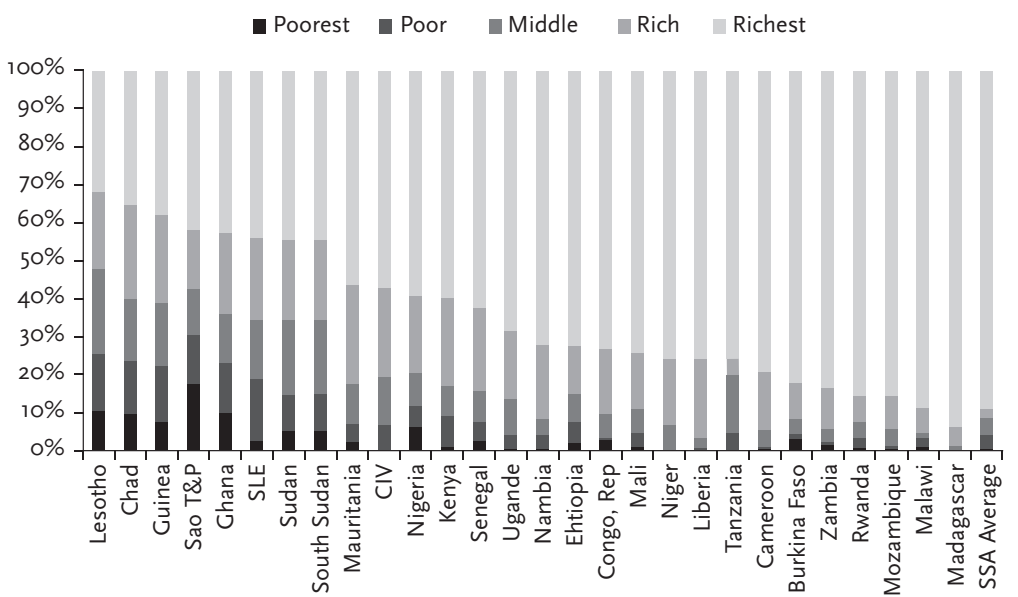

Source: Authors' calculations using household surveys.

\section{Equity by Wealth}

Tertiary education participation is predominantly limited to students from the highest income groups in all Sub-Saharan Africa countries. Figure io shows the share of tertiary enrolment by wealth quintile in 28 countries. In three-fourths of the countries, youth from the wealthiest households occupy over $50 \%$ of spaces in tertiary education, and youth from the top two wealth quintiles occupy nearly $80 \%$ of tertiary spaces. Individuals from the poorest households are five times less likely to have access to tertiary than individuals from the richest households. As a result, the overall GER in tertiary education is strongly determined by the GER of the highest income quintile in most countries. (See also Figure II.)

Sub-Saharan Africa shows inequity in tertiary education by income groups among sub-regions and groups of countries in inequity in tertiary education. (See Figure I2.) In general, middle-income countries show not only higher enrolment rates but also higher levels of participation among the lowest- and middle-level income groups when compared to participation level by these groups among the low-income countries. Furthermore, Anglophone countries show higher levels of equity. Among the sub-regions, East and West Africa show relatively higher levels of equity. It is noteworthy that, in middle-income countries and in West Africa, the household survey data show significant $(4.6 \%$ and $4.9 \%$ respectively) participation among the lowest-income groups.
Figure 11. Tertiary GER of highest income quintile and overall unadjusted tertiary GER.

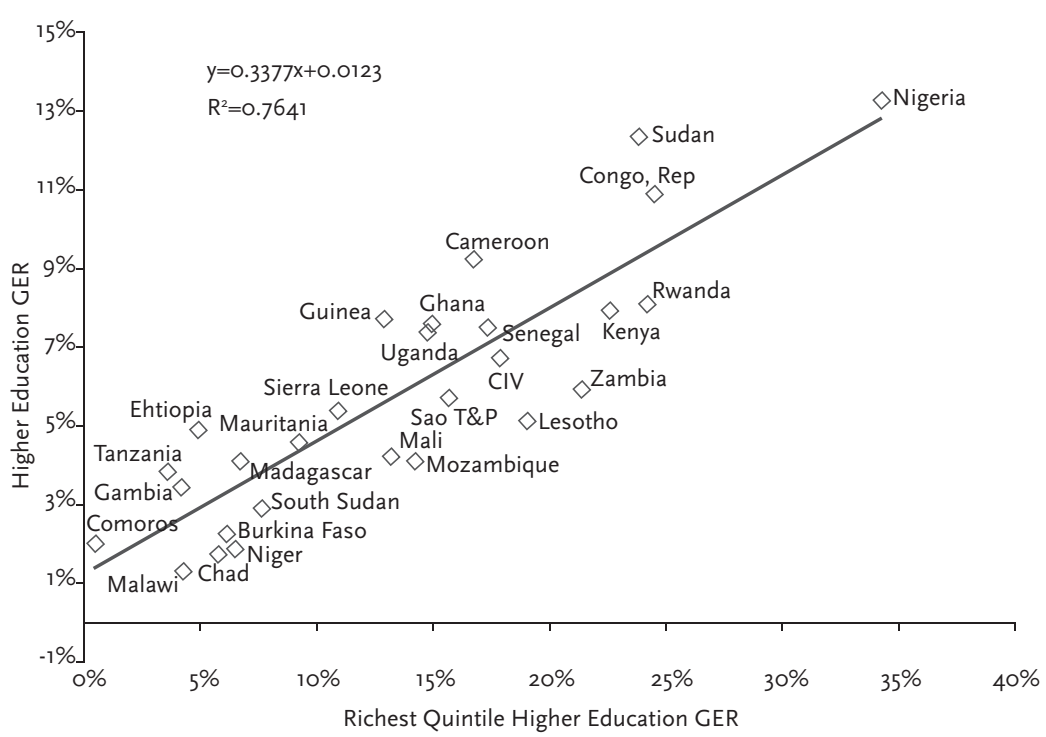

Source: Various household surveys.

Figure 12. Tertiary education GER by income quintiles.

- Lowest Middle Highest

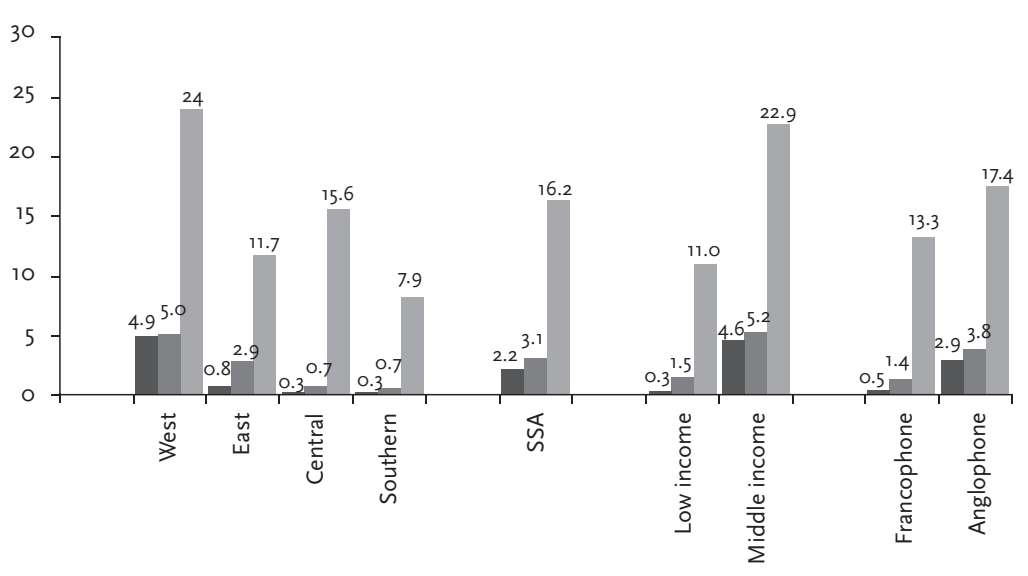

Source: Authors' calculations from household surveys. 
Figure 13. Tertiary education GER over time in four selected countries.

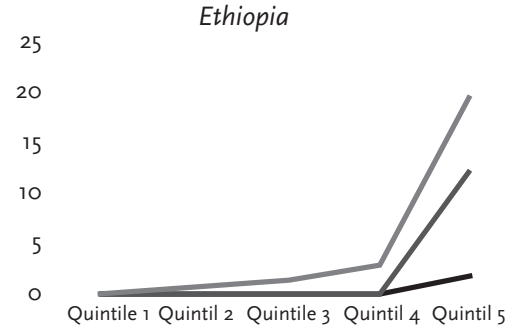

2000

Rwanda

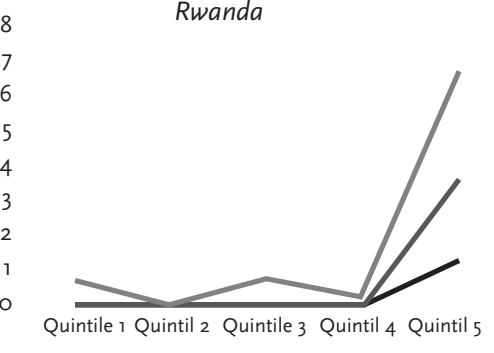

2000
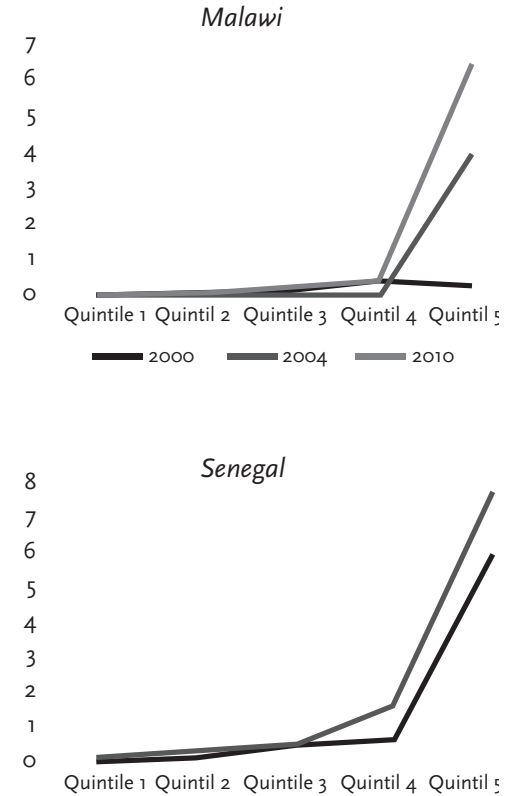

${ }_{2005} 2011$
$2000-2004$

Source: Various household surveys.

In many countries, inequity in access to tertiary education, in terms of household wealth, appears to have increased over time. While the postsecondary gross attendance rate has increased in most countries over time, youth from the highest income households have gained the most from the expansion of tertiary access in most countries. Figure I3 shows tertiary gross enrolment rates in Ethiopia, Malawi, Rwanda, and Senegal between 2000 and 2010-2012.

Countries could become more successful in expanding tertiary education by promoting access for the middle-level income groups. Compared to the dominance of enrolment by the highest income groups, countries show more variation according to their ability to promote access to middle-income groups. Uganda, Senegal, Ghana, and Côte d'Ivoire, all of which have relatively high overall tertiary participation rates, have increased access to tertiary education for the middle quintile. Mozambique, Ethiopia, and Rwanda have much lower participation irrespective of quintile-i.e., enrolment rates are
Figure 14. Tertiary GER of middle-income and highest-income quintiles.

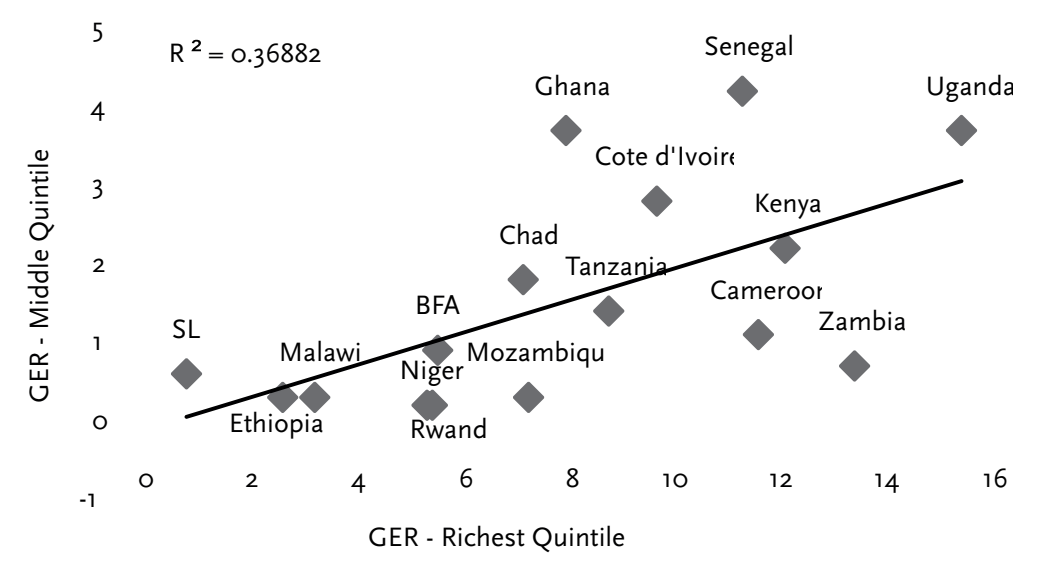

Source: Various household surveys.

low across income groups. (See Figure I4). These trends steer us to a working hypothesis that a more equitable tertiary education system requires policies that put more financial responsibility on the highest income groups and, on the other hand, provide income-based subsidies targeted to meet economic needs.

\section{Equity by Gender}

Participation of women is improving, albeit slowly, across the SubSaharan Africa region, but gender inequity is actually increasing in the region. Despite the improvements, Sub-Saharan Africa remains the only region where men increasingly outnumber women in tertiary education participation. The GER for women in Sub-Saharan Africa has increased from $3.5 \%$ in 2000 to $5.24 \%$ in 2010 at an annual growth rate of 5\%. (See Figures I5A and I5B). This growth of women's enrolment rates in tertiary education in Sub-Saharan Africa is growing more slowly than the global average of 6\%. Only the Arab States at 4\% and Eastern Europe and Central Asia (ECA) at 3\% report smaller growth rates for women; but both, especially ECA, started at a much higher enrolment rate. Because of the fast increase in the enrolment rate for men in Africa, on a regional level, gender parity is actually decliningdown to an annual growth rate of $-0.5 \%$. 
Figure $15 \mathrm{~A}$. Female GER in tertiary education.

80

70

60

50

40

30

20

10

\section{SSA SA Arab EAP World MENA LAC ECA OECD}

Source: EdStats (2013)

Figure $15 \mathrm{~B}$. Gender parity index by region.

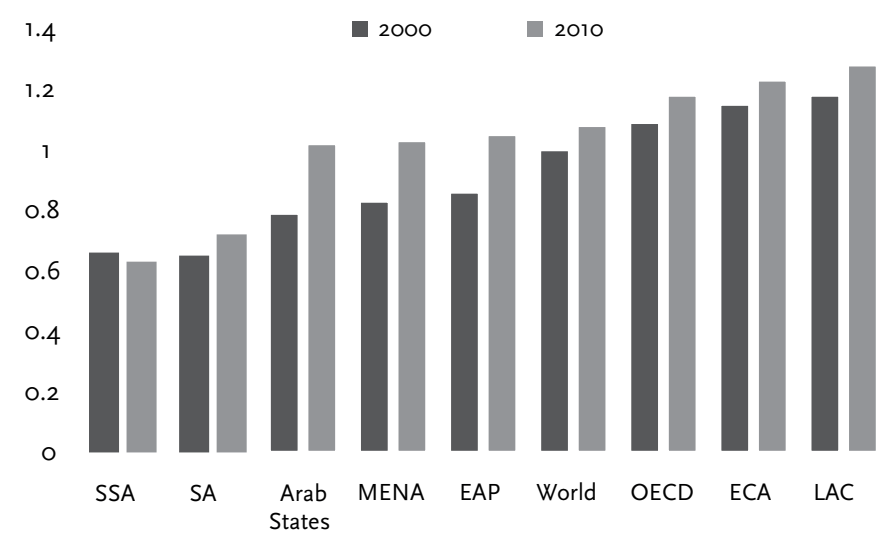

Figure 16. Gender parity index for tertiary education in selected countries 2000-2010.

0.9

0.8

0.7

0.6

0.5

0.4

0.3

0.2

0.1

$200020012002 \quad 20032004200520062007200820092010$

- Burkina Faso
- Cameroon
- Chad
- Ethiopia
- Chana
Kenya
....... Malawi
-.--- Niger
-..- Rwanda
..... Senegal

Source: UIS (2011)

Within the region, Sub-Saharan Africa countries are showing more promise. Nevertheless, gender parity remains, on the whole, elusive. Figure I6 shows the gender parity index for tertiary GER in selected countries from 2000 to 2010 (UIS, 20II). Countries where gender inequity was very low a decade ago (for example, Niger, Chad, or Ethiopia), have not shown significant overall improvement; and yearly changes have been rather erratic. In countries, where gender parity started above 0.5 (for instance, Uganda, Cameroon, and Rwanda), parity actually showed consistent improvements throughout the decade. Our hypothetical conclusion is that, in these countries, gender parity at the tertiary level is improved through consistent measures that show improvement in the pre-tertiary education of girls and young women. Consequently, unless lessons, including those at pre-tertiary level, from the more successful countries, are applied to countries with higher rates of inequity, the region as a whole will not reap the economic and social benefits that can usually be predicted from expanding women's participation in tertiary education. 
Figure 17. Tertiary GER by education attainment of head of household.

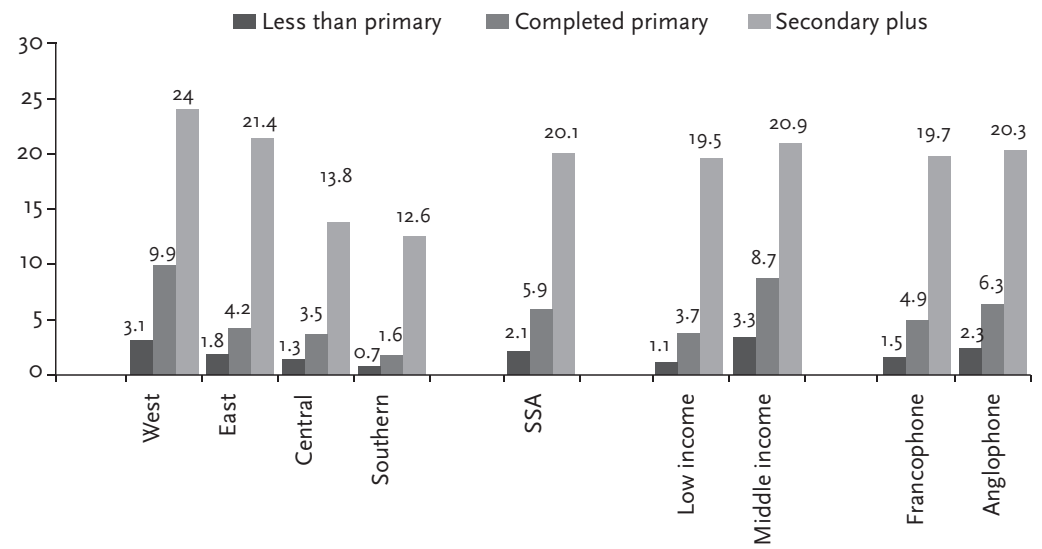

Equity by Parents' Education

Whereas tertiary education growth represents improved prosperity and competitiveness for countries, participation for individuals brings increasing inter-generational mobility. For young people, increasing education attainment can provide opportunities to find employment in the formal economy, earn higher wages/salaries, and break through the poverty barriers. However, if participation in higher levels of education is essentially "inherited" from one generation to the next, this type of inequity reflects persistent constraints of intergenerational mobility. Figure I7 shows the GER by the educational attainment of the head of household. It shows that young people from households where the head has at least a secondary education are much more likely to participate in higher education than those whose head of household did not complete primary education. Here too, middleincome and Anglophone countries show higher levels of equity; and among the sub-regions, West Africa seems to have achieved a higher rate of equity than the other sub-regions.

\section{Equity by Location}

A key demographic trend in Sub-Saharan Africa influencing educational attainment is the rapid migration from sparsely populated and poor rural areas to urban centers. (See Figure i8.) This trend has been further exacerbated by the expansion of tertiary education, which are mostly located in urban areas. But beyond that, youth attaining secondary education have a much higher likelihood to continue into
Figure 18. Location index (rural/urban) and GER.

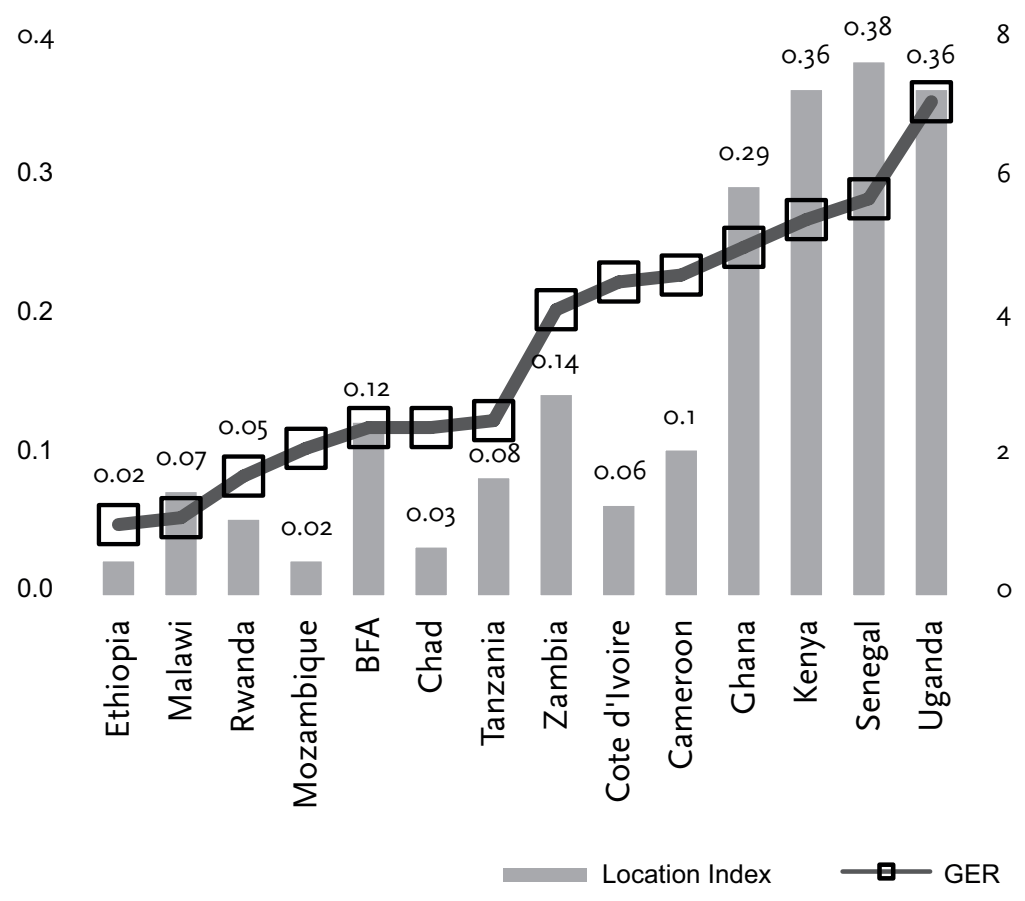

Source: Various household surveys.

tertiary-level education if they attain secondary education in better quality schools in cities. And finally, once young men and women graduate at tertiary level, they expect to find high-level professional employment also in cities. Consequently, the disparities in accessing tertiary education between urban and rural areas are heavily skewed towards the former by the rapid urbanisation of Sub-Saharan African countries. There are no easy solutions to counterbalance this trend, not only because educational demand is in the cities but also because employment following attainment is also concentrated there. Ghana, Kenya, Senegal, and Uganda appear to have the lowest disparity by location and also have the highest GER among the selected Sub-Saharan Africa countries. 
Table 2. Tertiary Education Enrolment by Location and Gender in 2010

\begin{tabular}{|l|c|c|c|c|c|c|}
\hline & \multicolumn{3}{|c|}{$\begin{array}{c}\text { Tertiary Adjusted Net } \\
\text { Enrolment Rate (NER) }\end{array}$} & \multicolumn{3}{c|}{$\begin{array}{c}\text { Tertiary Gross } \\
\text { Enrolment Rate (GER) }\end{array}$} \\
\hline Type of Locality & Both Sexes & Male & Female & Both Sexes & Male & Female \\
\hline All Localities & 4.6 & 5.1 & 4.1 & 9.1 & 10.8 & 7.5 \\
\hline Urban & 7.4 & 8.4 & 6.5 & 14.6 & 17.6 & 11.9 \\
\hline Rural & 1.1 & 1.2 & 1.0 & 2.5 & 3.0 & 2.1 \\
\hline Greater Accra & 9.1 & 9.7 & 8.6 & 17.6 & 19.9 & 15.6 \\
\hline Nothern & 0.9 & 1.1 & 0.7 & 2.3 & 3.0 & 1.7 \\
\hline
\end{tabular}

Source: Ghana Statistical Service (2013).

Ghana presents a typical case of fast urbanisation and migration to high economic growth areas. Here, the 2010 census calculated tertiary education enrolment rates, concluding that urban men have a GER of I7.6 \% while rural women have a GER of I\%. (See Table 2.) Furthermore, in Ghana the enrolment rate for women in the relatively poor northern region is less than $\mathrm{I} \%$ whereas men in the Accra region have an enrolment rate of almost $20 \%$.

\section{Equity Explained}

The previous section discussed a basic distribution of tertiary education enrolment by income, gender, parents' education, and location. The different countries and country groups of the region show some variations in the distribution, but some similar patterns emerge. Accordingly, participation in tertiary education shows persistent inequities despite the significant growth in tertiary education. We have also seen differences among countries. Some perform significantly better or worse than their neighbors.

Equity or inequity in tertiary education may be explained by accounting for extrinsic influences (such as social and economic trends) and intrinsic factors (such as those related to systemic characteristics of education) but also can result from the intended or unintended consequences of policies. In this section, we construct an analytical framework to account for these factors, gradually leading to the impact of policies. ${ }^{2}$ Among the important influences, we focus particularly on the impact of pre-tertiary education, the issues related to

2. Most of the analysis about the impact of policies will be completed in the next phase of our programme (forthcoming).
Figure 19. Secondary education GER

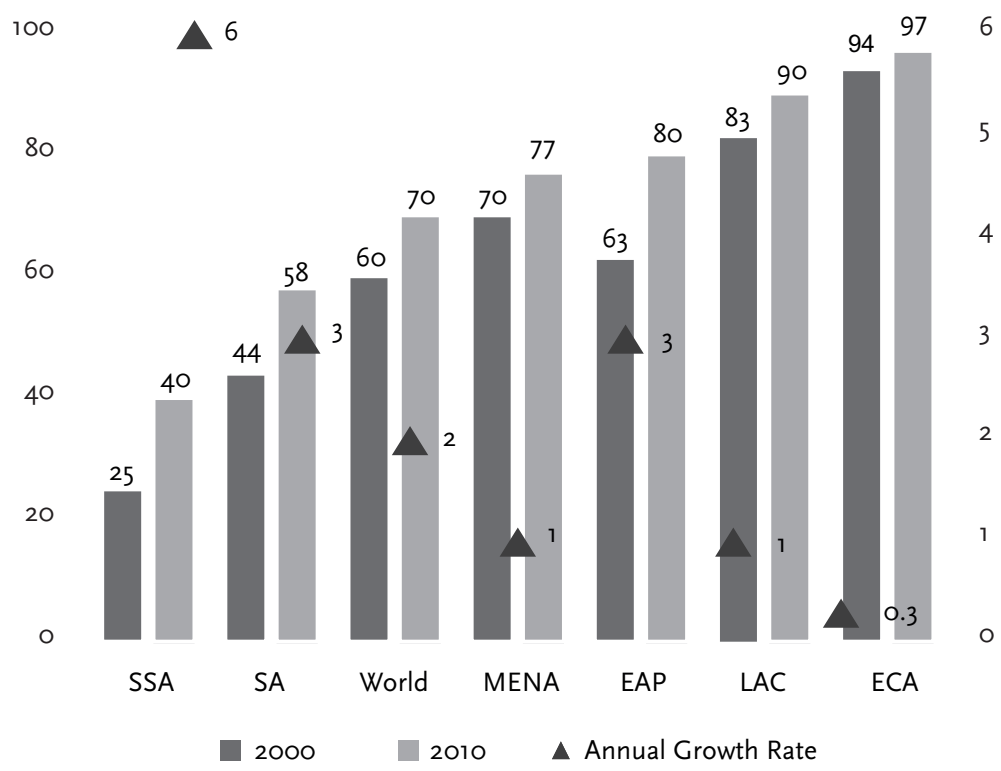

tertiary education structure and services, the different pathways available for individuals, and signals from the economy and labor market.

\section{Pre-Tertiary Education Growth}

Sub-Saharan Africa has made enormous strides in secondary enrolment; but the region still lags far behind other regions and the world average. Sustainable growth of tertiary education enrolment requires continuous and increasing demand from those graduating at the pre-tertiary level. Simply put, enough well-qualified candidates must graduate from high school to assure an adequate pool for tertiary-level applicants. The trends in secondary education enrolment for the past decade are presented in Figure I9. Secondary enrolment grew from $25 \%$ to $40 \%$ in the last decade for Sub-Saharan Africa-at an annual growth rate of $6 \%$.

This annual growth rate dwarfs the growth in every other region as well as the global average. Yet despite this significant progress, the low base from which Sub-Saharan Africa has started means that the region is a much further behind secondary enrolment compared to other regions. The closest region to Sub-Saharan Africa is South Asia, where the secondary enrolment rate stands at $58 \%$. Yet these figures are somewhat misleading as Africa's $40 \%$ coverage hides a relatively high 
Figure 20. Secondary/tertiary annual growth.

10

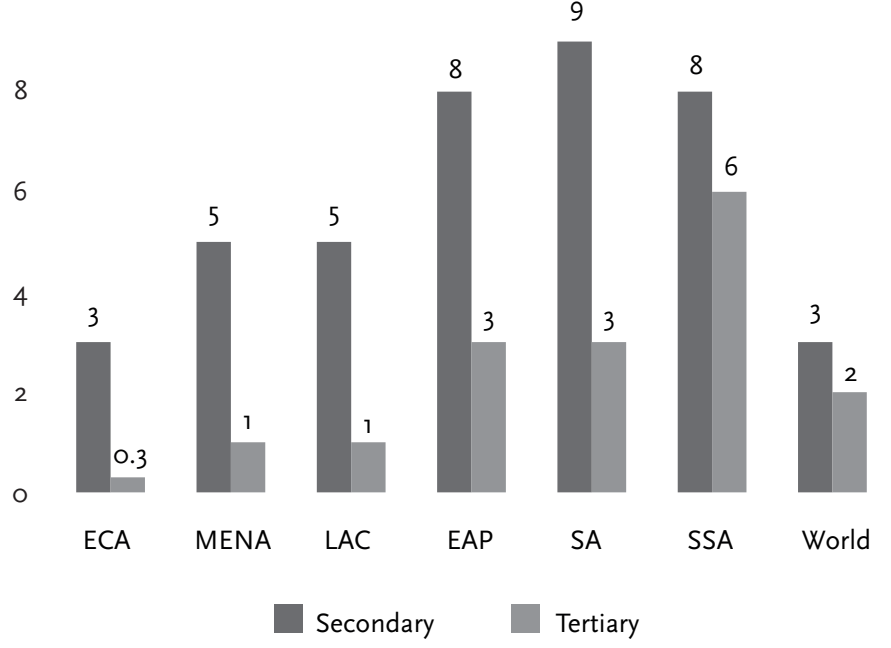

enrolment rate and faster annual growth at the lower secondary level (grades 6-7 to grades IO-II), which averages between $50 \%$ and $80 \%$, and low overall admissions to upper secondary education, which average between I0\% and 30\%. Still, secondary enrolment for this period grew at a much faster pace than tertiary education enrolment in the SubSaharan Africa region. (See Figure 20.) This pattern also means that growth at the tertiary level was more significantly instigated in SubSaharan Africa by increasing social demand (expressed by growth at secondary level) than in any other region in the world

But the need to expand tertiary education places heavy demands on the rest of the education system. In most countries, students' performance at the completion of their secondary education determines their entry to tertiary level. Universities and colleges expect a strong pool of candidates with solid academic, communication, literacy, numeracy, and other skills. If these skills are limited to a certain group of pretertiary graduates, admission to tertiary education will also be limited to such groups.

In Sub-Saharan Africa in general, the transition rates from the basic to post-basic level graduates and from the post-basic to the tertiary level of these graduates are lower than in other regions. Each of these levels represents a bottleneck. The most important of them is, by most accounts, the quality of basic education. Even in the best-performing
Table 3. Secondary Education Graduates Passing the Tertiary Education Qualification Examinations in Ghana (2009)

\begin{tabular}{|l|c|c|c|c|}
\hline $\begin{array}{l}\text { Senior High School } \\
\text { Ranking }\end{array}$ & Appeared & Qualified & $\begin{array}{c}\text { Percent } \\
\text { Qualified }\end{array}$ & $\begin{array}{c}\text { Percent of the } \\
\text { Total to Qualify to } \\
\text { Tertiary Education }\end{array}$ \\
\hline Top 20\% & 38,182 & 19,394 & $51 \%$ & $73 \%$ \\
\hline $21-40 \%$ & 33,227 & 4,589 & $14 \%$ & $17 \%$ \\
\hline $41-60 \%$ & 27,878 & 1589 & $6 \%$ & $6 \%$ \\
\hline $61-80 \%$ & 25,260 & 729 & $3 \%$ & $3 \%$ \\
\hline $81-100 \%$ & 24,799 & 233 & $1 \%$ & $1 \%$ \\
\hline Total & 149,346 & 26,534 & $18 \%$ & 100 \\
\hline
\end{tabular}

Note: Recalculated based on Djangmah (2009).

countries, only a minority of students acquire proficiency in key academic areas. The few African countries that expose their mathematics and language skills to international assessments generally perform two standard deviations below the global average. Moreover, upper secondary education has expanded significantly in size, but the disparities among schools are large. Once again, a majority of them do not provide adequate foundations for successfully transitioning to the tertiary level. For example, Ghana illustrates these large disparities. On average, only one student in five qualifies for tertiary education. The top $20 \%$ of the secondary schools have a tertiary education qualification rate of about $51 \%$. Almost $35 \%$ of the students in the bottom $40 \%$ take tertiary entrance examinations, but only $4 \%$ pass. The top $20 \%$ of the second schools provide over $73 \%$ of the students who are qualified for entry into tertiary education, while the bottom $40 \%$ provides less than $4 \%$ of the qualified students. (See Table 3.)

In essence, despite efforts to provide basic education for all and to expand post-basic education, both stages continue to be bottlenecks for tertiary expansion, especially in terms of their quality and external efficiency.

Low educational performance is determined by large disparities in service delivery rather than by the size of overall investment or inputs to basic and post-basic education. International assessments show that countries with fewer disparities and greater homogeneity in performance do better than those with a strong core of well-performing students but also a significant group of underperformers and a missing group of middle achievers.

Sub-Sahara Africa countries exhibit significant variations in the 
extent to which pre-tertiary education growth and transition explain tertiary education growth. In some countries like Uganda, secondary education has not grown fast enough and thus remains relatively elitist, with the result that the tertiary enrolment rate is higher than the regional average. In a number of countries, tertiary education seems to be a bottleneck (i.e., high upper secondary GER, low tertiary GER). In most countries of the region, upper secondary education appears to be a bottleneck (low upper secondary GER, low tertiary GER). Only a few countries (Ghana, Cameroon, and Kenya) show a relatively favorable balance between the two rates. We could demonstrate this balance by the ratio between secondary and tertiary GER in individual countries and globally. In sum, low education attainment in the adult population appears most often directly correlated with low secondary school achievement. Almost always in the selected countries, access to secondary education appears to be a bottleneck that reduces access to tertiary education. While Ghana and Kenya are among the countries that have been more successful in retaining students for the final year of secondary education and have a relatively high tertiary enrolment, other countries do not match this trend, and no clear pattern or policy suggestion emerges.

The inequity in tertiary education is driven by a variety of constraints that young people face as they pass through their school career on their way to the labor market. These constraints are distributed unequally among different social groups. They include educational constraints, economic constraints, supply constraints, and also constraints set by the labor market.

\section{Educational Inequities at Pre-Tertiary Level}

The previous section described how the growth of pre-tertiary education may affect tertiary education expansion. Other potential pre-tertiary-level bottlenecks are related to inequities in the quality of learning, completion of secondary education, and making a successful transition to higher levels of study. Keith Lewin (2007) coined the term "zones of exclusion" to identify key factors that cause particular subpopulations of students to drop out or become at-risk of dropping out.

As an example, Ghana has one of the best performing basic educational systems in the region, yet only one third of its students have adequate proficiency in basic academic areas (mathematics, sciences, language, and humanities) to access upper secondary education. Only about one quarter of its students start upper secondary education on time; and of those attempting to pass the upper secondary completion examination, more than half fail in mathematics and sciences.
On average, one in five graduates from secondary schools transition to the tertiary level. Not surprisingly, these students are generally the best ones. In countries where secondary education is more selective and the final exam is more rigorous, the transition rate is higher; and in countries with less selective secondary systems, it is lower. But in most countries, successful transition is the privilege of a few who benefited from the best secondary education schooling options.

Socioeconomic differences in choosing upper secondary schooling options persist. Typically students from low-income families have low expectations and make poor choices (Ajayi, 20I2). Our analyses also show that affluent families typically choose high-quality private schools beginning at the basic education level and benefit more from public subsidies at the post-basic level in high-performing public schools (World Bank, 20II). These choices lead to inefficiencies as high-performing but poor students have a lower likelihood of reaching tertiary education than average-performing students from more affluent families.

Fees and out-of pocket payments are the most obvious economic constraints for students seeking to enter tertiary education. However, two less obvious but more significant economic constraints are paying for quality pre-tertiary education and social disparities in opportunity costs. Given that these two factors are less visible, policymakers may either ignore them or have no effective means to address them.

Better-off families are well advised to buy better quality pre-tertiary education-or better outcomes from public education-by opting for private education or paying for private tutorial services to better prepare their offspring for make a successful transition to higher levels. This race, in effect, starts at pre-school, given that most education systems are incapable of helping students overcome initial handicaps in reading comprehension and basic numerical skills.

Second, the increased pressure on expanding tertiary education forces institutions to generate non-public revenues. In addition to tuition charges, tertiary fees often must cover meals and housing, course registration, laboratory and other educational resources, exams, etc. These fees plus other out-of pocket payments often block access to tertiary education for the poor; even without tuition fees, such costs could be as much as half of the total tertiary education costs.

Most successful students from poor households start and complete their pre-tertiary education at a much later age. They are, in fact, lucky if they start tertiary education in their mid-2os and graduate before they reach age 30 . For these students, the opportunity costs are much 
higher than for the offspring of wealthier families. These poorer students are expected to contribute to household income and often have spouses and children who require support. These opportunity costs could make even planning for tertiary education unrealistic.

\section{Labor Market Constraints}

The growth of tertiary education is based on the expectation that both public and private sectors require a larger workforce of well-educated professionals. (See Figures 2I, 22, and 23.) For the public sector, the expansion of social services and the increasing complexity of public administration create a demand for tertiary graduates. In the private sector, the desire to become globally competitive, the orientation towards exporting trained professionals, the adoption, use, and development of new technologies, and the increasing demand for complex products and services in both global and domestic markets all call for the expansion of tertiary education and research.

In most Sub-Saharan Africa countries, the increase in tertiary enrolments and in tertiary education attainment has not translated into a comparable improvement in employment opportunities. The mismatch between the number and type of graduates and the needs of the labor market may lead to unemployment, underemployment, and long school-to-work transitions. In some Sub-Saharan Africa countries, the higher the educational level, the higher the incidence of unemployment (Amelewonou \& Brossard, 2005). This is the case in Côte d'Ivoire, Nigeria, Tanzania, Madagascar, Cameroon, Mauritania, Niger, Senegal, and Uganda, where tertiary graduates have higher unemployment rates than youth with only primary or secondary education. In Benin, Sao Tomé and Kenya, tertiary graduates have unemployment rates comparable to those of secondary graduates and much higher rates than primary graduates or youth with no education at all (Fares et al., 2005).

The phenomenon of unemployment among tertiary graduates is mostly concentrated in urban areas and is referred to as the "educated youth hypothesis" (Leibbrandt \& Mlatsheni, 2004). Most graduates come from privileged backgrounds and can afford to remain unemployed while searching for positions that match their expectations in terms of wages and prestige. The rates of unemployment among the tertiary graduates also indicate that, while the tertiary education sector is producing an increasing number of graduates, the labor market does not seem to be generating employment requiring tertiary education at the same rate. In Ghana, the STEP Skills Measurement Survey in 2013 carried out among 2,000 urban households confirmed the educated
Figure 21. Urban youth educational profile by labor market status, Ghana, 2013.

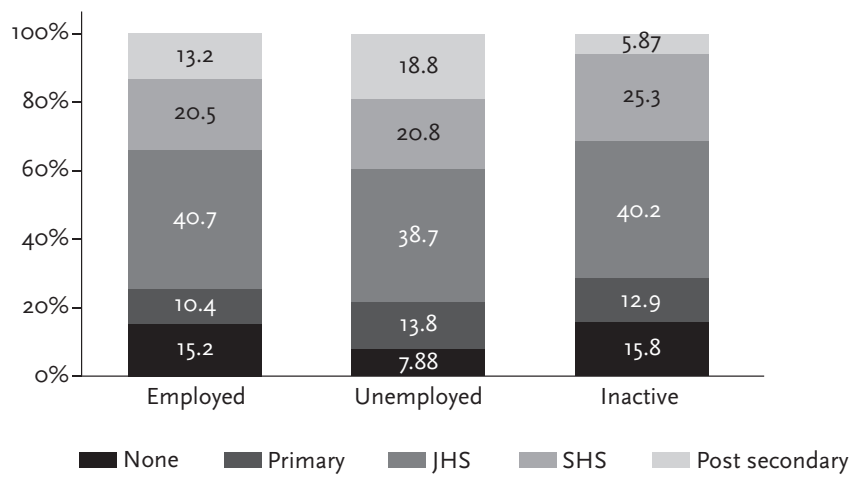

Source: Authors' calculations (with Marta Favara) based on STEP Skills Measurement Survey (Ghana, 2013)

youth hypothesis, meaning that a greater proportion of tertiary-educated youth were more unemployed than employed, although only a small proportion of those not actively looking for jobs had achieved tertiary education. (See Figure 2I).

Constraints in the structure of the labor market among those in different types of employment are even more significant. In most SubSaharan African countries, the majority of people are self-employed. Self-employment does not promise an attractive career option for tertiary education graduates. There is a positive relationship between wage employment and the rate of enrolment at tertiary level. Countries like Lesotho and Sao Tomé and Principe had a much higher wage rate and very low tertiary GER; others like Nigeria and Sudan had a high tertiary GER but relatively small size of wage sector.

To indicate more details about the relationship between employment and education, we analysed recent census and household data from Ghana. With rates of about $16 \%$ rate of wage employment and about $7.5 \%$ GER, Ghana was at Sub-Saharan Africa's average in both; and the relationship between the two by and large followed the regional statistical trend. (See Figure 22.) Here, about $60 \%$ of the men and $70 \%$ of women were self-employed. (See Figure 23.) We discuss the impact on earnings below. In contrast, a quarter of adult men and a little more than Io\% of women were in the wage sector, according to the 2010 census. 
Figure 22. Share of wage employment and tertiary education GER

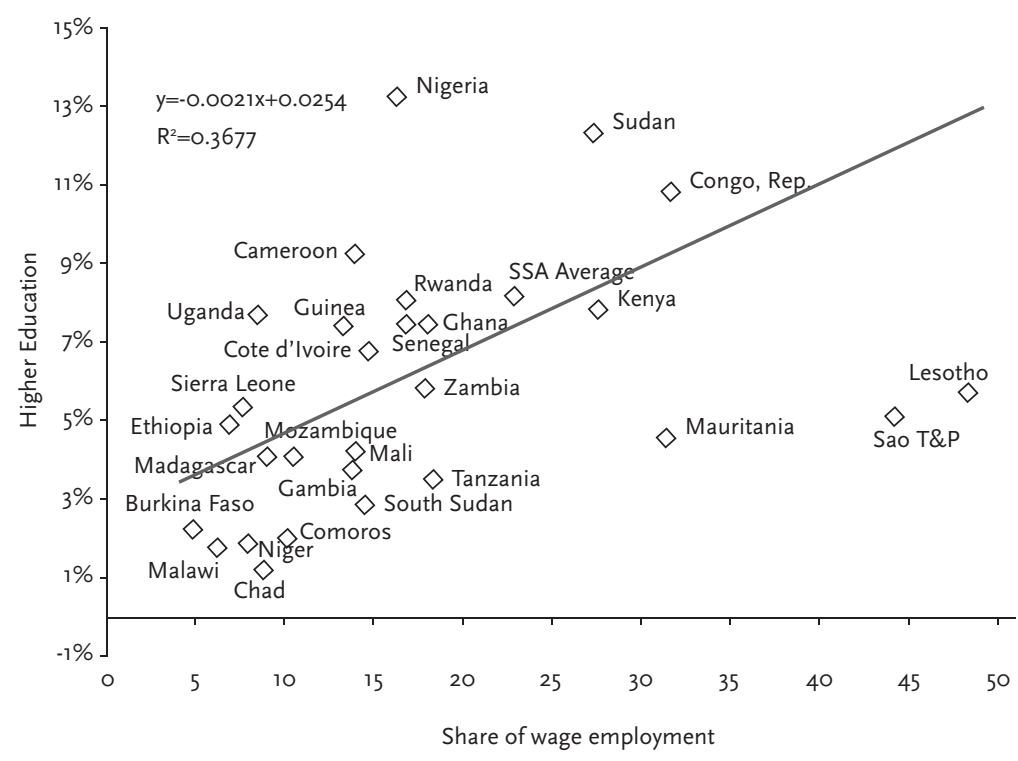

Source: Authors' calculations based on household surveys.

Figure 23. Employment status in Ghana according to the 2010 census.

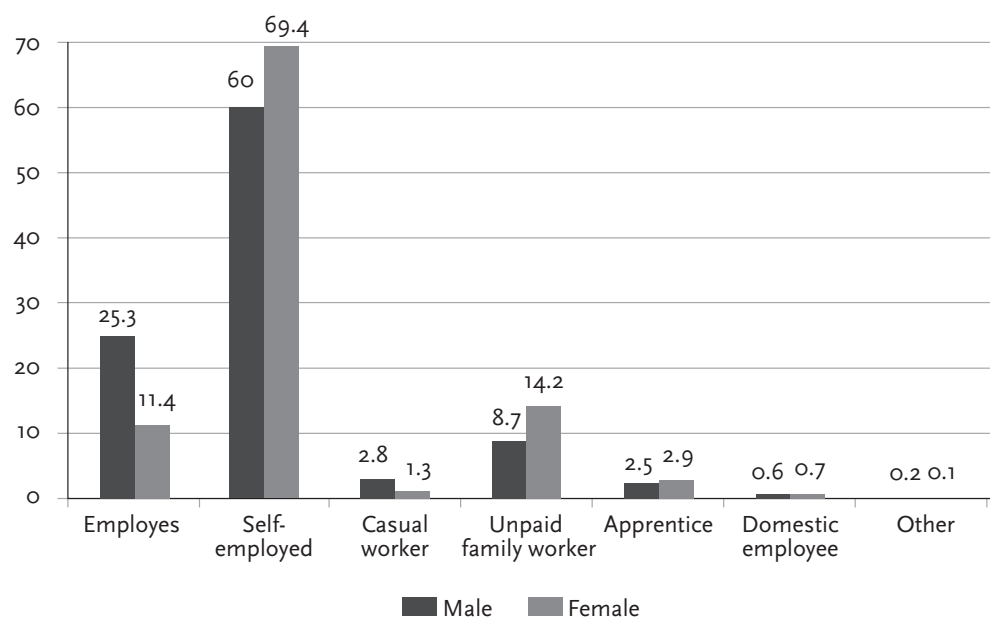

Source: Ghana Statistical Service (2013).
Table 4. Employment Sector of Household Heads by Gender in Ghana, Census Data 2000-2010

\begin{tabular}{|l|c|c|c|c|c|c|}
\hline \multicolumn{4}{|c|}{ Total } & \multicolumn{2}{c|}{ Male } & \multicolumn{2}{c|}{ Female } \\
\hline Sector & $\mathbf{2 0 0 0}$ & $\mathbf{2 0 1 0}$ & $\mathbf{2 0 0 0}$ & $\mathbf{2 0 1 0}$ & $\mathbf{2 0 0 0}$ & $\mathbf{2 0 1 0}$ \\
\hline Public & 9.6 & 8.7 & 10.8 & 9.7 & 6.5 & 6.6 \\
\hline Private formal & 14.6 & 8.4 & 15.4 & 10.3 & 12.7 & 4.3 \\
\hline Private informal & 74 & 82 & 71.7 & 79 & 79.7 & 88.6 \\
\hline Other & 1.7 & 1 & 2 & 1.1 & 1.1 & 0.4 \\
\hline Total & 100 & 100 & 100 & 100 & 100 & 100 \\
\hline N & $3,052,266$ & $4,585,293$ & $2,170,609$ & $3,132,907$ & 881,657 & $1,452,386$ \\
\hline
\end{tabular}

Source: Chana Statistical Service (2013).

In most countries in the region, even in the wage sectors, the economy is dominated by the informal sector, a situation which holds limited attraction for tertiary education graduates. Only countries with fair economic diversification and exposure in manufacturing have significant growth in formal private sector employment (i.e., countries like South Africa, Mauritius, and Kenya). Other countries that have demonstrated high economic growth rely predominantly on natural resources or on other commodities, which typically do not have high labor intensity or high skills demand. Typically, for instance, Ghana had sustained a high level of growth during the past decade based on commodities; and during this period, employment in the formal private sector significantly declined. (See Table 4.)

For tertiary education graduates, the public sector has proven to be the most robust and reliable employer. The scope of employment growth in the public sector is in line with the growth of public services. These typically include education, health, communal services, and public administration. It seems likely that the growth of these services accelerated during the last decade and a half, but further growth will be limited. In other words, the absorption capacity of the public sector is limited and will probably reach saturation in the not-too-distant future.

As Table 4 shows, in Ghana, where public services are extensive, public employment declined slightly during the last io years, although this decline does not seem significant. The educational background of these employment options weights the opportunities for tertiary graduates towards the public sector. (See Figure 24.)

While the growth in public sector employment is determined and, to some extent contained, by the growth of public sector services, the growth of private sector employment is contained by limited productiv- 
Figure 24. Educational profile of the urban adult population in Ghana

A. Self-employed/wage workers

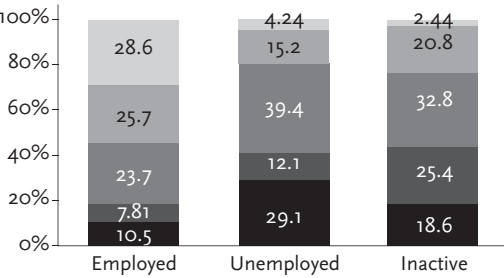

C. Public/private sector employees.

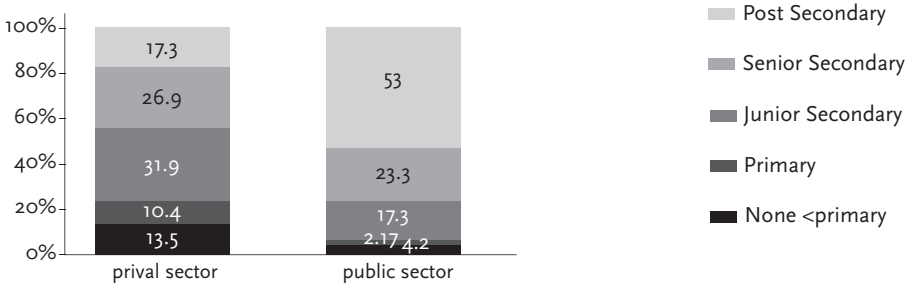

Source: Authors' calculations (supported by Marta Favara) 2013 STEP Skills Measurement Survey (Ghana, 2013).

ity, the inability to scale up, a limited ability to invest in technology, and other market failures. As a result, the formal private sector in most SubSaharan countries is still in its infancy. The majority of enterprises are informal; manufacturing and services are comprised of mostly small enterprises that are presently not in a position to absorb the excess output of tertiary graduates. The informal nature of the private sector in Sub-Saharan Africa also poses questions about the utility and relevance of highly skilled labor. Candidates and their families ask if it is worthwhile to invest money, time, and stress in higher education if they are most likely (if lucky) to find employment unrelated to their study fields and are highly likely to establish their own businesses. It is noteworthy that, whereas governments are trying to encourage matriculation in various STEM-related fields of study, students tend to avoid these areas for fear of high standards and limited job opportunities.

Tertiary education seems to have a strong effect on the graduates' ability to find employment in the formal sectors, whether they are private or public. However, within the formal sectors, the private formal economy is not always growing fast enough in some Sub-Saharan Africa countries and there is also a natural ceiling for the growth of the public sector. As long as government policies fail to address the constraints of private sector growth, the skills and degrees acquired by tertiary graduates will not be absorbed fast enough, and tertiary education will continue to benefit the few who are either able to join the public sector or able to find high-level professional jobs in the private sector. But both opportunities are limited. For the majority of youth, even getting to the tertiary level poses risks, high opportunity costs, outof-pocket payments, and some risks that no jobs will await them upon graduation. The growth of the private formal economy depends on how successful countries are in diversifying their economy. Also, as far as the informal sectors and self-employment are concerned, they are typically constrained by low productivity and the limited use of skills and technology. Consequently, absorbing tertiary graduates may be helped by better aligning tertiary programmes to the characteristics of the labor markets and by economic policies that improve labor productivity in the informal economy.

Earnings, Benefits, and Costs of Tertiary Education and Equity

The existence of the economic benefits of tertiary education is well established; and adequately capturing and analysing these benefits, estimating the costs, and evaluating their impact on policy has a long history among education economists. Yet in the context of Sub-Saharan Africa and in the developing world in general, we do not yet have a clear and robust analytical framework that explains variations and changes in the economic benefits of tertiary education either for individuals or for larger communities. This analysis will not deal in depth with methodological issues and will not take sides in the debate between various approaches to analysing the economic benefits. Our focus is on the implications of various findings for equity and later, in a forthcoming second-stage study, on equity-focused policies.

Analyses of economic rates of return using a relatively "simple formula" (Psacharopoulos, I98I) of different levels of education, especially in the I970s and I980s, generally argued that the more lifetime benefits in earnings are related to costs, the stronger the justification for government intervention and public investment (Psacharopoulos, I973, I982). The simplest formula takes into account the full costs (including foregone earnings or opportunity costs) and the benefits measured in lifetime earnings. At times, when public resources were limited compared to the numerous needs for public investment (health, infrastructure) and when access to primary education was far 
Figure 25. Tertiary education's relationship with wages.

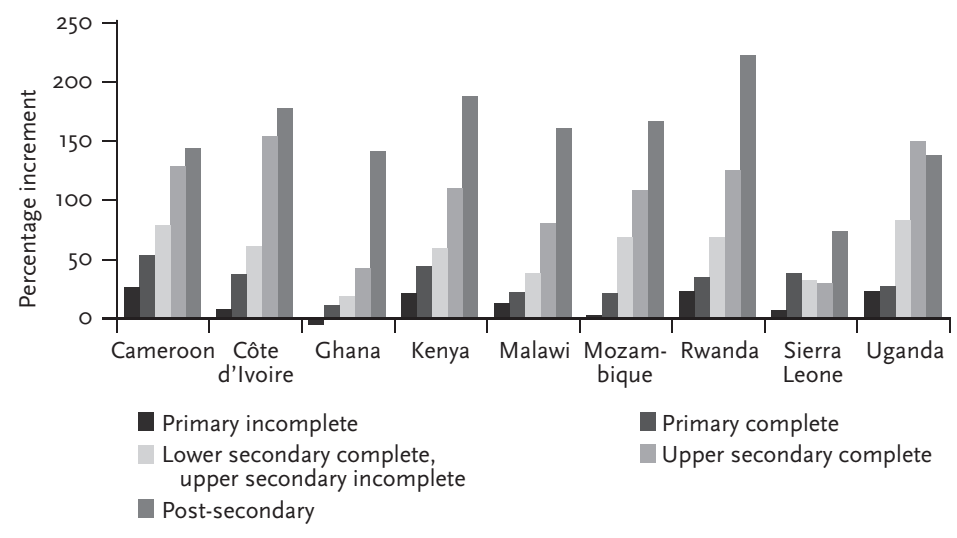

Note: Hourly wages among wage workers by level of education, contrasted to workers without education (Filmer \& Fox, 2014, p. 73).

from universal, the recommendation was to cut back on public subsidies to post-basic and tertiary education and invest predominantly at the primary level. This focus, combined with macro-level structural adjustment programmes led to decay in the tertiary sector and mistrust between the higher education community in Sub-Saharan Africa and multinational agencies like the World Bank.

Our collective understanding of the economic benefits and costs in education has since improved and rate-of-return models and methodologies have gained complexity. These changes in methodology developed in parallel with the evolution of the region's education systems and with improvements in accessing education at all levels from basic to tertiary. Short of attempting to be comprehensive, we see the following distinctions as important.

First, labor market rigidities and distortions, especially the largescale informality, may both limit the short-term benefits of education and skills on earnings and also cloud our full understanding on both the cost and the benefit sides. Accordingly, despite limited information on how formal education attainment would lead to improved earnings, it seems likely that individuals benefit from the skills they acquire and that other factors affect marginal benefits that may be difficult to account for. For instance, finishing one level of education may be an entry condition to a higher level of education with higher returns. Some educational benefits may be boosted by increasing work experience, or by investment in production technologies that comple-
Figure 26. Earning difference between secondary and tertiary education graduates.

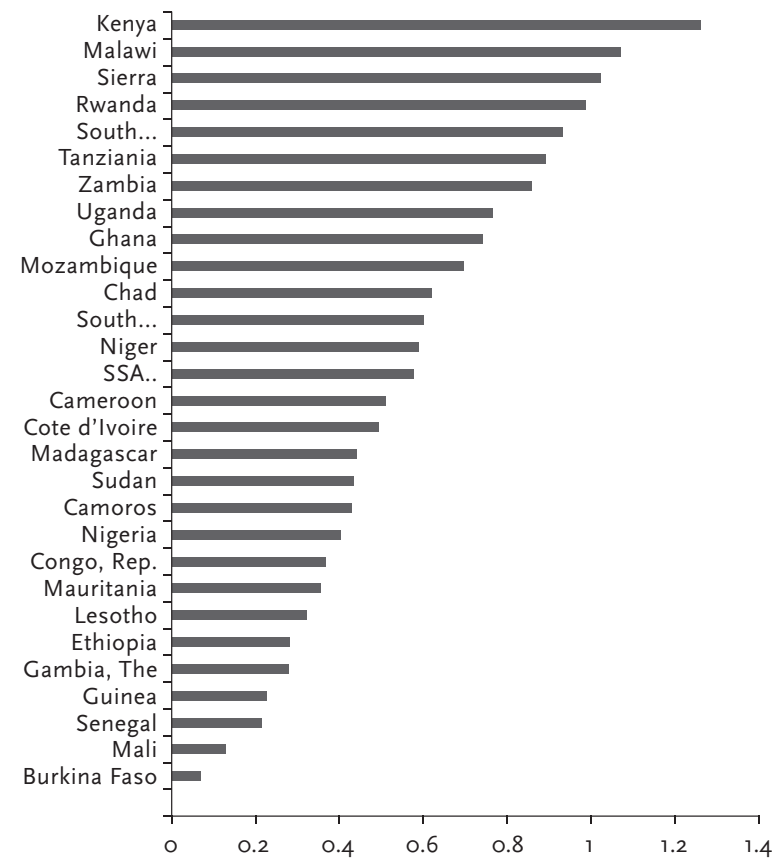

Source: Authors' calculations using household surveys.

ment higher skills. Similarly, on the cost side, the analytical models improved as costs were divided between the direct beneficiaries and taxpayers' public expenditures.Also, even while labor markets showed little improvement in Sub-Saharan Africa, the expansion of public services and the solid economic growth in some countries created a reliable "market" for education and skills. (See Figure 25.) This economic growth inevitably led to increases in incomes and a wider spread of incomes.

Second, the more diversified the economies, the greater the opportunity for improved absorption and higher earnings. As a result, in the last decade, even while earnings for post-basic education remained somewhat constrained in some countries by large-scale informality, earnings for tertiary education graduates have significantly improved, and large variations have emerged between countries in the region (Diagne \& Diene, 20II). (See Figure 26.) 
Figure 27. Earnings for the urban population in Ghana by education.

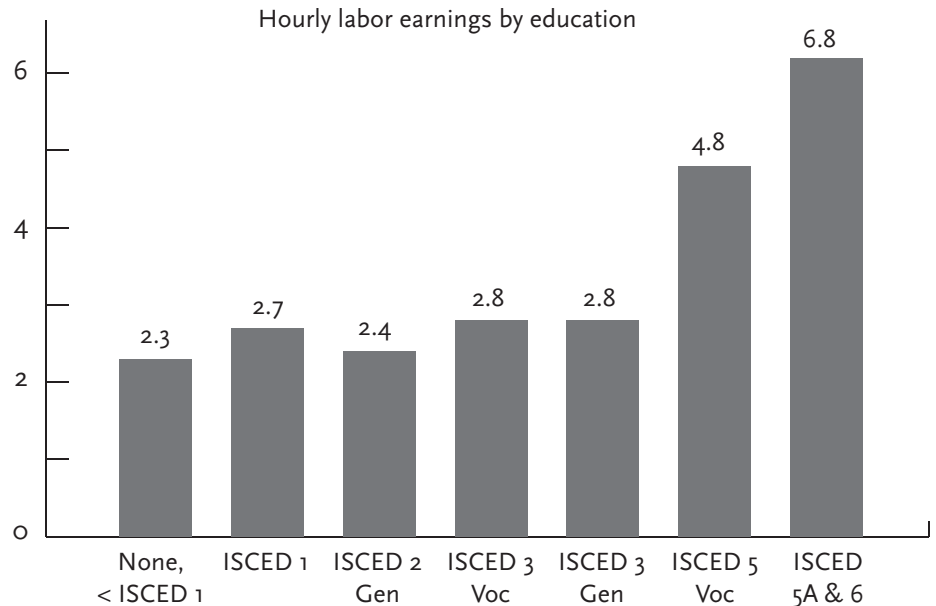

Source: Authors' calculations (with Marta Favara) based on STEP Skills Measurement Survey (Ghana, 2013).

Using again the Ghana case study, the STEP Skills Measurement survey showed that only tertiary education attainment produces a significant earnings premium. (See Figure 27.) When analyzing the urban adult population in a country with significant constraints on the formal private sector (discussed above), earning premiums are significant only for tertiary education graduates, the majority of whom are employed in the public sector.

Third, the growth of tertiary education and improvements in earnings provide a sharper focus on the gap between public and private benefits, costs, and returns. As discussed above, those private benefits include the marginal changes in lifetime earnings, while increasing consumption and costs include out-of-pocket payments, fees, and charges as well as opportunity costs. Capturing public benefits and costs is more difficult. Public benefits or public goods benefit society, including increased tax revenues, improved quality and effectiveness of public services, and positive influence on such areas as public health, public safety, or civic and community behavior. On the costs side, public costs include all public expenditures including public financing of tertiary education services and public subsidies (scholarships and demand-side incentives) of students.

The macro-economic argument is that the public financing of tertiary education is justified when the public returns are higher than the private returns. Given certain market failures, such as externalities, inequities,

Figure $\mathbf{2 8}$. The ratio of private to social returns by level of education.

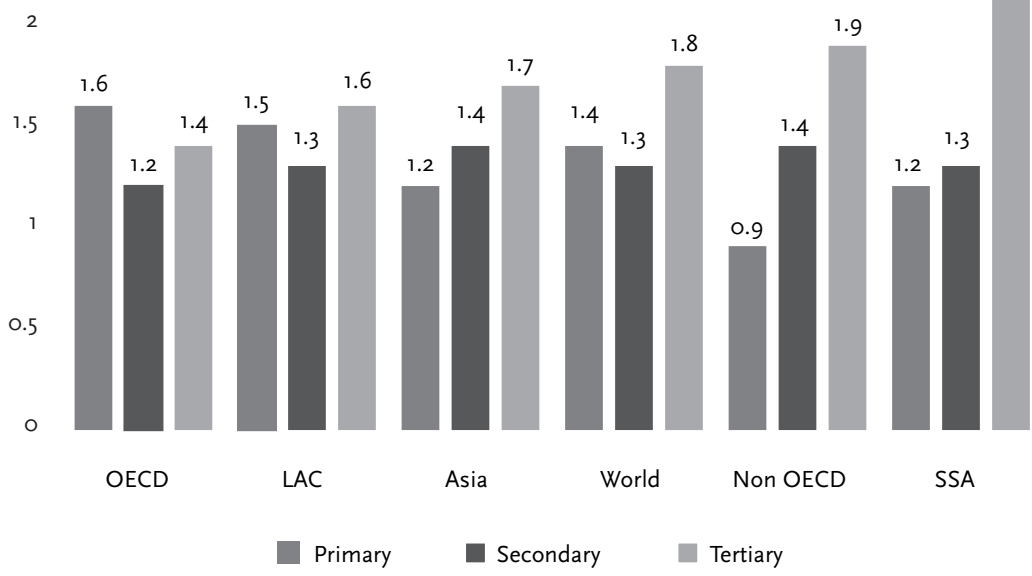

Source: Psacharopoulos \& Patrinos (2002)

and information asymmetry, private investment in higher education does not reach the maximum benefit that includes public benefits. In other words, there is a market failure in the sense that public goods are associated with tertiary education.

In Sub-Saharan Africa, tertiary education is predominantly financed by the state, as discussed below. Because of escalating costs to the public and the limited number of beneficiaries, public returns and benefits to the many are dwarfed by the private returns to the few. Figure 28 compares the ratio of private and public returns across continents and shows that the difference between private and public returns to higher education is much higher in Sub-Saharan Africa than in other continents or in the world.

Labor market rigidities make opportunity costs for the poorer majority of the Sub-Saharan Africa societies particularly high and put tertiary education attainment beyond reach for them. Accordingly, the private benefits and costs for these groups are different than for the more affluent groups, even though the public or social returns to tertiary education may be maximised especially through these lower-income groups. In sum, policies that achieve a better balance between social and private returns-within income groups-make tertiary education fairer and more equitable. 


\section{Equity Addressed}

The previous section showed that inequity in the tertiary education system is a consequence of the inequities present from the pre-tertiary level, beginning with primary education. Tertiary education systems are at the tail end of a selection process that starts before children even begin their formal schooling and is further strengthened through years of education. Therefore, tertiary education is, to some extent inherently equitable, especially for systems that did not go through massification. Smart policies will not suddenly change this profile; policies will not, nor should they, follow a big-bang approach. Instead, a range of policy options gradually mitigates this inequity starting before students actually reach tertiary education and may include policies that go beyond tertiary education. This section does not provide an in-depth review of such policies_-giving only a rough list with some regional trends. In the second phase of our analysis, which will be forthcoming, we conduct an in-depth review of the specific policies that either address equity directly or have an impact on equity.

\section{Structure and Equity of Pre-Tertiary Education}

Differences between the structure of education and the transition from secondary to tertiary in Anglophone and Francophone countries can have inequity effects at the tertiary level. In Anglophone countries, the entry into tertiary education has stricter requirements-that is, finishing secondary education does not guarantee entry into tertiary education, while in Francophone nations, passing exit examinations at the upper secondary level, guarantees a place in the tertiary system. But exit examinations drastically reduce the pool of candidates available for the tertiary level. While the upper secondary enrolment rates are relatively similar for both sets of countries, Anglophone countries show, on average, a higher tertiary enrolment rate than Francophone countries. In Francophone countries, admission to tertiary institutions is often automatic following graduation from secondary level (i.e., the successful completion of the baccalaureate exam); and the generous funding of scholarships by universities creates incentives for students to enroll and to stay enrolled in tertiary institutions. Selectivity is greater in Anglophone countries (such as Tanzania) where admission quotas have become more frequent and strategic than in Francophone countries.

\section{Diversification of Tertiary Education Systems}

The structure of tertiary education, non-university programmes, services outside the main urban centers, and the structure of study fields all affect the extent to which countries can open up tertiary education
Figure $29 \mathrm{~A}$. Distribution of tertiary students by programme type.

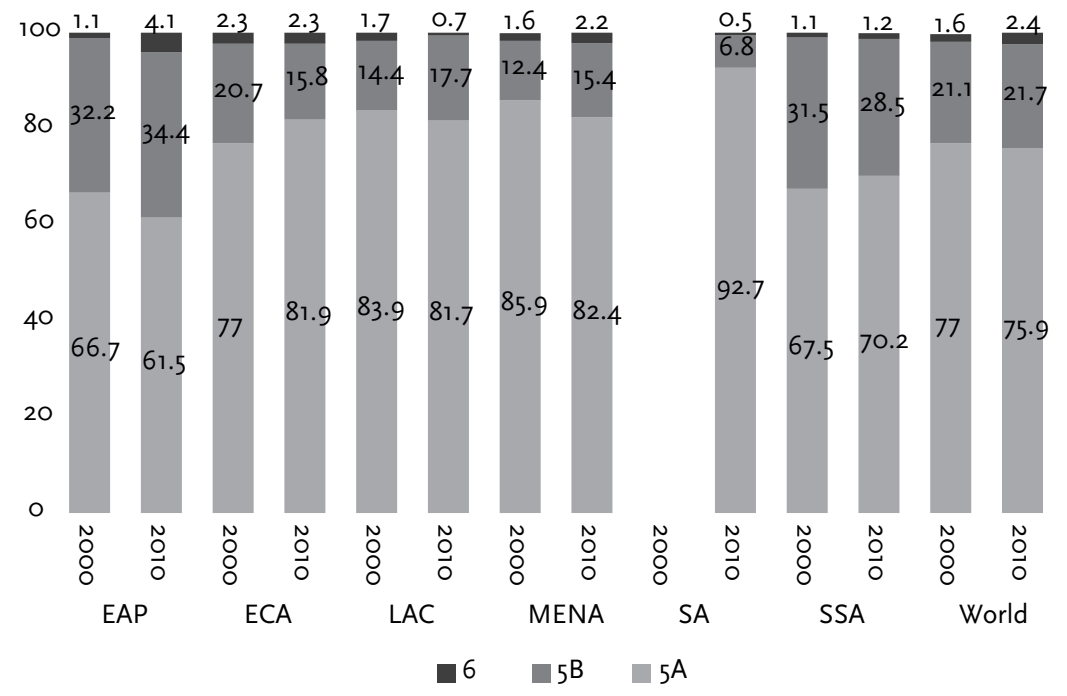

Source: EdStats (2013)

Figure 29 B. Proportion of non-university tertiary enrolment ISCED ${ }_{5} B$ in Sub-Saharan Africa countries in 2012

Share of ISCED 5/B

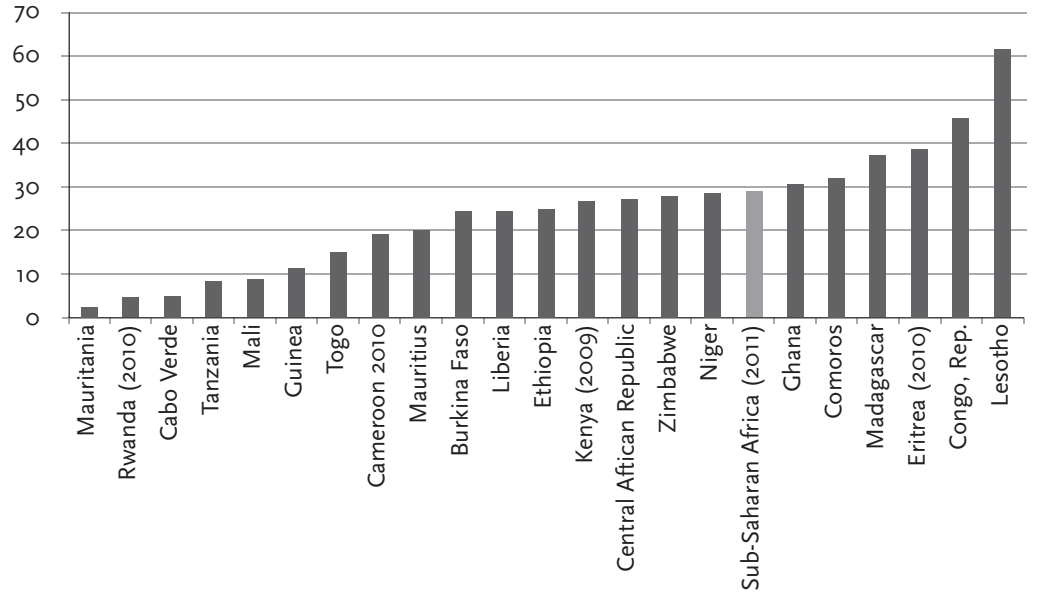

Source: EdStats (2014). 
to those groups and generations which have had no or limited access before. Three important and observable trends are associated with the diversification of tertiary education in Sub-Saharan Africa: (a) institutional diversification and the strengthening of the non-university sector, (b) the development of open and distance learning, and (c) the application of new technologies.

Institutional Diversification. The non-university sector has a long tradition in Sub-Saharan Africa. Technical and professional education has been present alongside universities, educating cadres for integration in corporate, non-public-service professions. Enrolment to non-university institutions is especially high in Anglophone countries (e.g., Ghana, Kenya, Nigeria, and South Africa) where the education system is more strongly focused on private sector needs. Enrolment did not grow as fast in the more selective non-university institutions in Francophone Africa. These institutions predominantly focus on the specialised needs of the public sector and are managed and financed by ministries other than the Ministry of Education-e.g., Ministry of Agriculture, Industry, etc. (Shabani, 2006).

Programme Diversification. This education level does not lead to a university degree, and students are generally older than upper secondary students. But this solution may be a cost-effective way to prepare students to achieve tertiary education if they are unable to qualify for it after secondary education.

Non-university programmes can be an option by which policymakers improve access, equity, relevance, and even sustainability of tertiary education. These programmes are typically shorter, cheaper, and better aligned with labor market needs for larger numbers of well-trained technical and administrative staff for both the private and public sector. According to the UNESCO-sponsored International Standard Classification of Education (ISCED), ${ }^{3}$ Sub-Saharan Africa has a relatively high percentage of students enrolled in technical programmes compared both to other regions and to the world average (See Figures 29A and

3. ISCED 5-A programmes are largely theoretically based and are intended to provide sufficient qualifications for gaining entry into advanced research programmes and professions with high skills requirements. They have a minimum cumulative theoretical duration of three years; they typically require that the faculty have advanced research credentials: and they may involve completion of a research project or a thesis. ISCED 5 B prosmmes are than ISCED 5 A programmes. They do not prepare students for direct access to advanced research programmes, they have a minimum duration of two years, and their programme content is typically designed to prepare students to enter a particular occupation. ISCED 6 programmes are tertiary-leve studies that lead to the award of an advanced research qualification.
Figure 30. Tertiary GER and percentage of distribution of students in the nonuniversity sector.

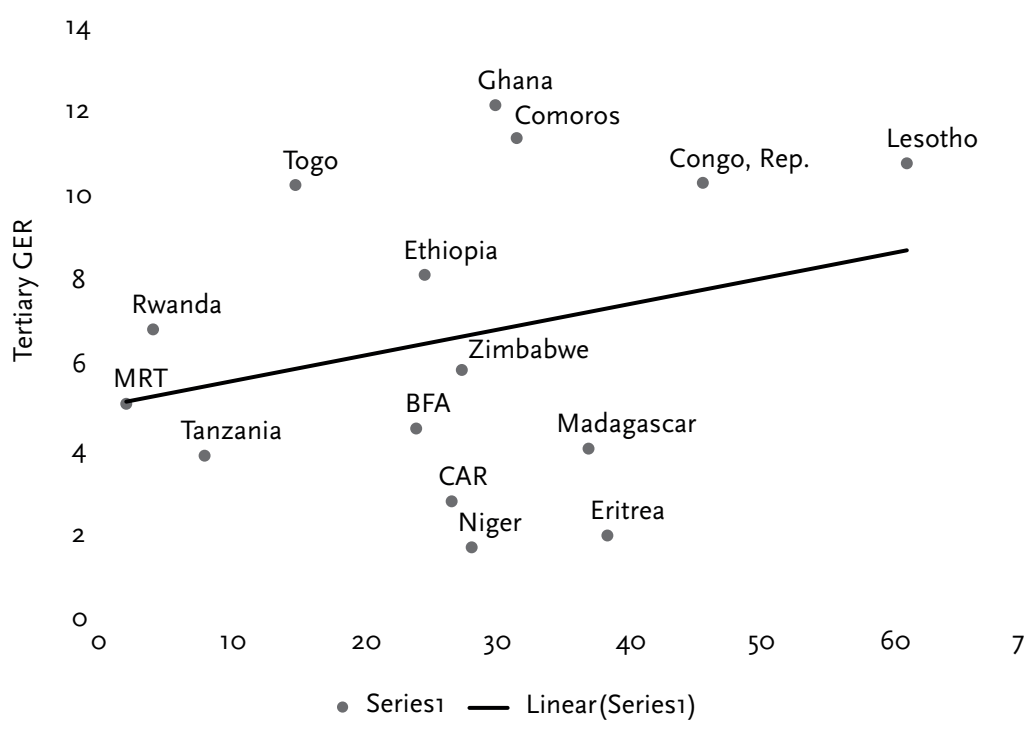

Distribution of Students (\%), ISCED 5 B

Source: EdStats (2014).

29B). In 20I2, 29\% of tertiary students in Sub-Saharan Africa were enrolled in non-university programmes. The only region with a higher share of technical programme tertiary enrolments was East Asia and Pacific with $32.2 \%$, while the world average was $21 \%$.

Countries with relatively high tertiary enrolment rates also appear to have high rates of enrolment in the non-university sector. (See Figure 30.) However, the relationship is not statistically significant, and analyzing both the outliers and those closer to the trend line is equally important. For example, Ghana has a high enrolment rate but low nonuniversity share while Niger has a low GER but high non-university share.

Open and Distance Learning (ODL). In addition to the emergence of the non-university and private sectors, Sub-Saharan Africa has experimented with distance, on-line and cross-border education. While important initiatives have emerged sporadically (e.g., African Virtual University), Sub-Saharan Africa has not been able to match the expansion of these initiatives at a level comparable to that of other regions 
Figure 31. Share of private tertiary education enrolments in Sub-Saharan Africa in 2011.

Share of private higher education in enrolment

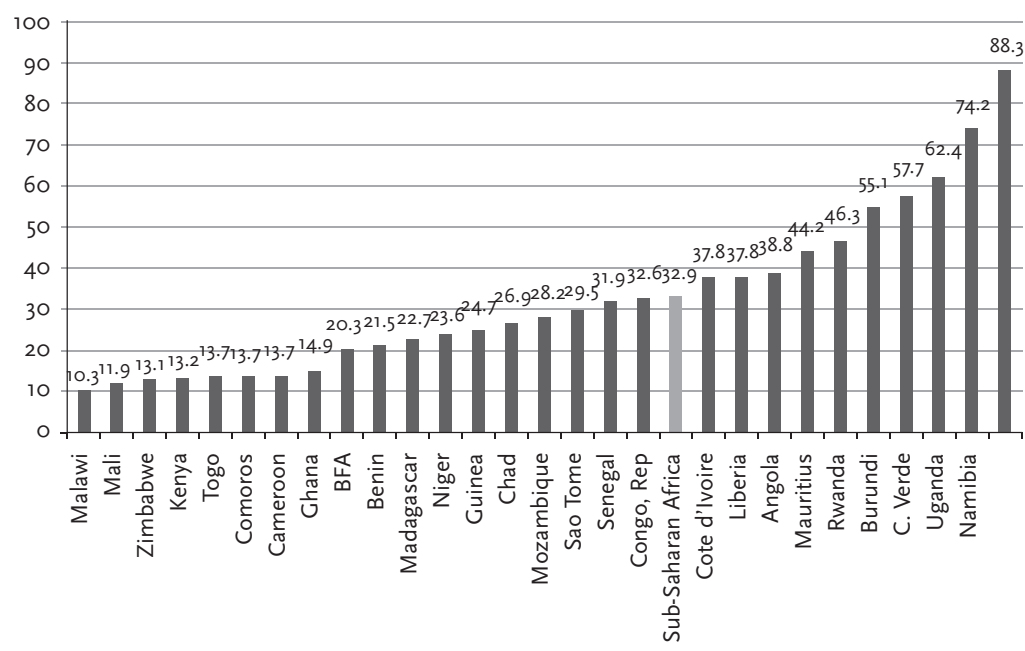

Source: EdStats (2014)

Figure 32. Enrolment in private higher education by percentage and tertiary GER.

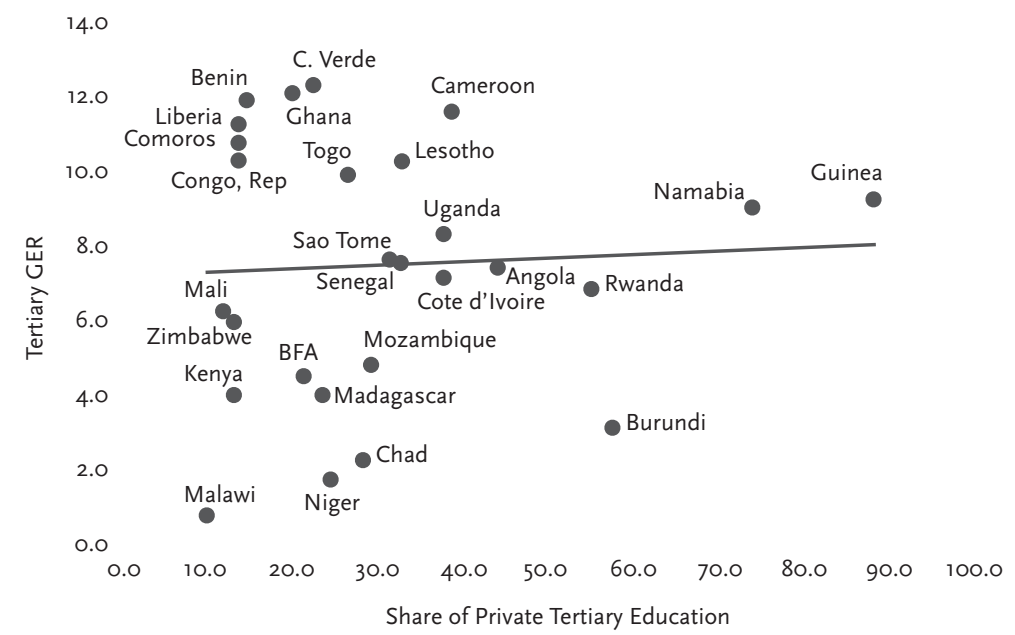

Source: EdStats (2014) like East Asia and Latin America. The key constraints are the cost of educational technologies, the lack of information and communication technology (ICT) infrastructure, and the purchasing power of the population. Open and distance learning could be a long-term viable solution to problems of access and the cost-effective provision of tertiary education, but only if costs decline as a result of more open and competitive ICT markets.

\section{Private Higher Education}

The expansion of the private sector in Sub-Saharan Africa originated with legislation of the early I990s that allowed for the private provision of higher education. Prior to the I990s, the few existing private universities in Sub-Saharan Africa were religiously affiliated, but the I990s saw the emergence of not only non-religious private institutions but also of for-profit private higher education (LaRocque, 2000; Levy, 2003)

There is no clear relationship between the share of private tertiary education and the gross enrolment rate at the tertiary level. The variations in the share of private tertiary education enrolment rates are caused by differences in definitions, the role of the private sector, and the characteristics and quality of private tertiary education providers. The share of enrolment ranges from Mali, Malawi, where private education enrolments constitute hardly more than Io\% of the total enrolment, to Uganda and Namibia where private institutions dominate total enrolments (See Figure 3I). As Figure 32 shows, whereas Mali does have a very low GER and low private share, a large number of countries (Benin, Cameroon, Ghana, Comoros, Lesotho, and Togo) have a low private share but high GER. Burundi has a high private share, but its GER is still lower than the Sub-Saharan Africa average.

The share of private enrolment in tertiary education does not appear to have a negative effect on equity; in fact, its impact on equity may actually be positive. We used the share of female enrolment as a proxy of equity. As Figure 33 shows, there seems to be a positive relationship between the share of private enrolment in tertiary education and gender equity. Further analysis will be needed to explain the country-specific policies on private tertiary education and their intended or unintended implications on equity.

\section{Tertiary Education Financing}

Whereas overall investment levels and differences in unit costs do not necessarily explain variations in equity, various financial modalities, public subsidies, and the balance between costs and the financing of 
Figure 33. Share of private tertiary education and share of female enrolment in SubSaharan Africa countries.

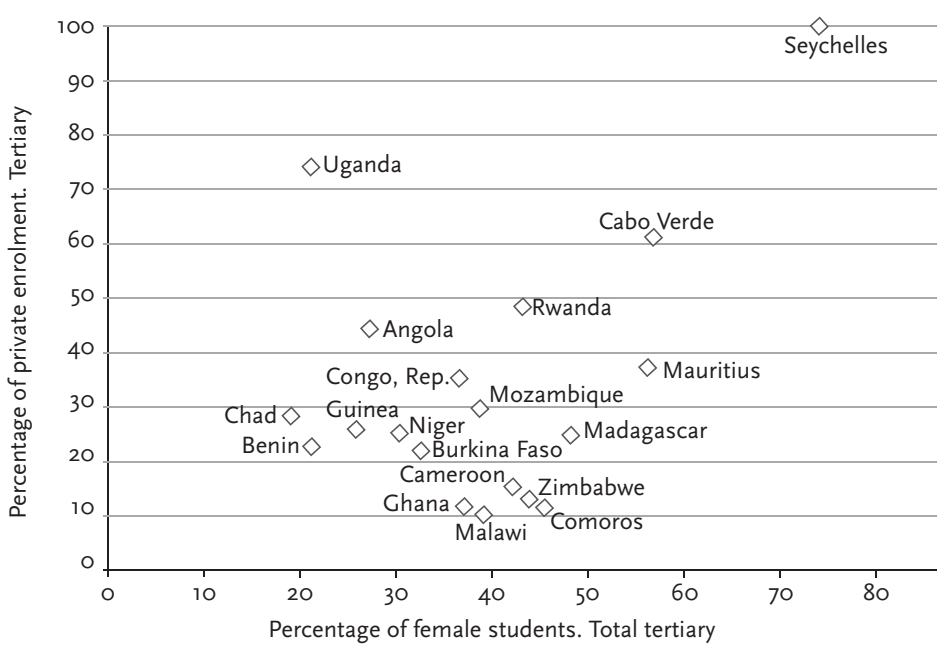

Source: EdStats (2014).

various levels of education do. The Sub-Saharan Africa region allocates a larger portion of its total public budget to education compared to the other regions. In 2008 , average spending on education constituted I $8.9 \%$ of all government spending; the SSA countries range from $4 \%$ in Equatorial Guinea to $27 \%$ in Tanzania, an increase of I.8 percentage points over almost two decades. In I990, education's share of public spending was, on average, I7.I\%; and in 2002, the share rose to approximately $17.6 \%$. This high share of spending allocated to education shows a rather strong commitment on the part of African countries to improving education.

All other world regions allocate less to education in terms of the total public budget. The Middle East and North Africa (MENA) region allocates approximately $\mathrm{i} 8.6 \%$ of its government budget to education while Europe and Central Asia allocate approximately i $2.4 \%$, a decrease of around $2 \%$ in two decades. These figures may, however, be out of date; the last available regional average for OECD countries and Latin America and the Caribbean was 2002.

Despite the increase in education's average share of public spending in Sub-Saharan Africa, spending on education as a percent of GDP/ capita has declined over the past two decades. Sub-Saharan Africa spending on education in terms of GDP/capita declined to $3.8 \%$ in 2008 from a high of $5.2 \%$ in 1990 and $4.7 \%$ in 2002 . In comparison,
Figure 34. Annual unit costs of tertiary/annual unit costs of primary education and tertiary education gross enrolment rates.

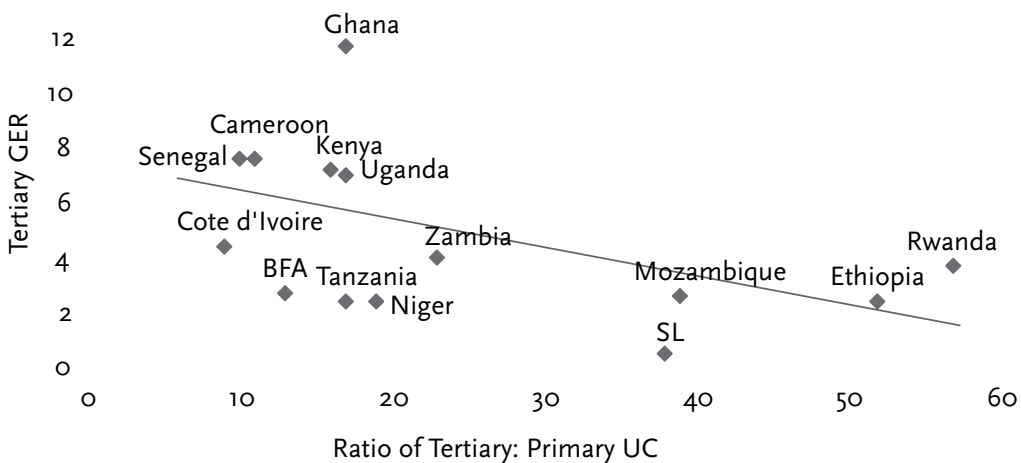

Source: Various household surveys and EdStats (2013).

all other regions of the world, with the exception of South Asia and the Middle East and North Africa, have actually increased the share of education spending in their GDP. Only East Asia and Pacific and South Asia spend less on education than Sub-Saharan Africa in terms of GDP/capita. Lesotho (ז2\%); Botswana, Burundi, and Swaziland (8\%); and Kenya and Tanzania ( $7 \%$ ) have the highest public education spending as a percentage of their GDP whereas Equatorial Guinea, Central African Republic and Zambia (ז\%) spend the least.

There is an inverse relationship between tertiary education growth and the proportion of tertiary education spending in total education spending in Sub-Saharan Africa. In a forthcoming study, we will examine tertiary education unit costs for non-Sub-Saharan Africa countries. Figure 34 shows how the relatively high unit cost of tertiary education (as calculated as a proportion of primary education unit costs) is related to gross enrolment rates. In essence, countries that spend between Io and 20 times more on a tertiary-level student than on a primary-level student (including countries like Kenya, Uganda, and Ghana) typically have higher enrolment rates than countries like Sierra Leone, Mozambique, Ethiopia, and Rwanda that spend 40 to 60 times more on tertiary students than on primary students annually. Consequently, these countries also have a larger fiscal space in which to increase access and also improve equity, assuming that they have similar economic growth patterns.

Given the trajectory of the expansion of education and other public services and the current rate of economic growth, the increasing number 
of higher education students in the future and the current model of financing in Sub-Saharan Africa is unsustainable for the future. In 20I5, there will be approximately 20 million more higher education students compared to the number in 2006 (Devarajan, Monga, \& Zongo, 20II; World Bank, 20I0). A recent study calculated the projected education costs for a sample of 27 countries in 2015 . Using 2004 costs as a constant, that study estimated that, in 20I5, countries will spend \$9I4 million (2004 US\$), an increase of \$320 million over what was spent in 2004. This sum does not include resources that must be spent on infrastructure and staffing to manage the influx of new students. As mentioned earlier, a major reason for government support of higher education is to ensure that the private benefits of higher education are shared by poor students and are used as a means of ascending the income ladder or escaping poverty.

An average of $43 \%$ of public funding in tertiary education goes to students from the top Io\% of the population. In fact, in several of the countries, the number is higher than this average. Ethiopia, Rwanda, and Malawi are all examples of countries where almost $60 \%$ or more of the public funding on tertiary education goes to the richest Io\%. On the lower end of the spectrum are South Africa and Mauritius in which only $20 \%$ or less of the funding goes to the richest I0\%.

Cost-sharing in tertiary education is a natural progression for tertiary education financing in Sub-Saharan Africa. The reasons include improved fairness (both expenditures towards tertiary education and public taxation appear to be regressive), improving access to welldeserving students who do not have the means to access tertiary education, and offering arguments of both efficiency and sustainability. The cost-sharing mechanism means that the cost of tertiary education is borne by all the stakeholders-parents, students, and society (or the government). Cost-sharing implies the introduction of tuition fees or at least a dual-track tuition fee system where either some fields are priced higher or where paid tertiary seats are an option for anyone who does not qualify for a free/merit seat.

In Sub-Saharan Africa, the concept of cost-sharing is gaining acceptance. Twenty-six countries currently charge fees (either tuition or other types) for tertiary education. Approximately $30 \%$ of income for universities was derived from fees as of 2009 ; the portion ranges from $5 \%$ in Madagascar to $75 \%$ in Guinea-Bissau (World Bank, 20I0). In addition, countries have adopted a dual-track policy in which some university places are offered at no or low cost (generally based on merit or need) while other places come with tuition fees. Francophone Africa has traditionally upheld the notion of free tertiary education, but there are exceptions. For example, Benin has universities that charge tuition fees. Francophone countries also tend to have more financial assistance for both tuition costs and living expenses.

It is imperative that cost-sharing does not further exacerbate tertiary education inequity. To avoid inequities, cost-sharing must be accompanied by instruments that will ease tertiary education entry for students who are already disadvantaged in terms of access-minorities, women, rural students, and students from lower-income families and from families whose parents have no higher education qualifications. These instruments include financial aid in the form of tuition fee waivers, scholarships, living stipends, and student loans. The loan system is a work in progress since there are still problems stemming from verifying eligibility, loan recovery, information asymmetry, and the cost of repayment (compared to salaries).

It is important to have programmes and/or policies that target students in pre-tertiary education as a means of reducing inequity in access and assuring quality in tertiary education. This report has already demonstrated the importance of pre-tertiary education on tertiary education growth. Hence, bridge or outreach programmes could be a key in ensuring that students, regardless of their backgrounds, have access to good quality tertiary education. The programmes should not only address challenges in academics or financing that create barriers, but also provide information on the options available to students in tertiary education. We have seen that students, who come from households where the parents/guardian has a higher educational level, have an advantage in accessing tertiary education. These students already have a leg up when it comes to information on fields of study, financial aid options, and other knowledge that could prove crucial to a firstgeneration student contemplating tertiary education. The bridge or outreach programme can also specifically target disadvantaged groups, providing them with extra tutoring or support to bring them up to tertiary standards. Finally, given the rising importance of STEM subjects, programmes used in developed countries such as the United States, not only target disadvantaged groups for access, but also encourage their access to specific fields of study, especially STEM subjects.

\section{References}

Ajayi, K. F. (2012). School choice and educational mobility: Lessons from secondary school applications in Ghana. Unpublished PhD dissertation, University of California Berkeley.

Amelewonu, K., \& Brossard, M. (2005). Développer l'éducation secondaire en Afrique : Enjeux, contraintes et marges de manœuvre. Pole de 
Dakar. Report prepared for the Regional Workshop on Secondary Education in Africa, November 2I-24, 2005, Addis-Ababa, Ethiopia. Quoted by Mathieu Brossard-Borel Foko PÔLE DE DAKAR (UNESCO-BREDA): Costs and Financing of Higher Education in Francophone Africa 2008 The World Bank Africa Human Development Series (the original report is no longer available on the internet.)

Bloom, D., Canning, D., \& Chang, K. (2005). Higher education and economic development in Africa. Draft report prepared for the World Bank. Washington, DC: World Bank.

Devarajan, S., Monga, C., \& Zongo, T. (20II). Making higher education finance work for Africa. Journal of African Economies (AERC Supplement 3), 20(3), I33-54.

Diagne, A., \& Diene, B. (20II). Estimating returns to higher education: A survey of models, methods and empirical evidence. Journal of African Economies (AERC Supplement 3), 20(3), iii8o-iiirz2.

Djangmah, J. S. (2009). Inequitable access to basic education in Ghana: The way forward for free compulsory universal basic education (FCUBE), CREATE, Centre for International Education, Department of Education, School of Education \& Social Work. Essex House, UK: University of Sussex, Falmer.

EdStats. World Bank Education Statistics. (20I2). http://datatopics. worldbank.org/education/

EdStats. World Bank Education Statistics. (20I3). http://datatopics. worldbank.org/education/

Fares, J., Guarcello, L., Manacorda, M., Rosati, F., Lyon, S., \& Valdivia, C. (2005). School-to-work transition in Sub-Saharan Africa: An overview. Understanding Children's Work Working Paper. Rome: Understanding Children's Work.

Filmer, D., \& Fox, L. (20I4). Youth employment in Sub-Saharan Africa. Africa Development Series. Washington, DC: World Bank.

Ghana Statistical Services. (20I3). Women and men in Ghana: 2010 population and housing census report. Accra: Ghana Statistical Service.

LaRocque, N. (2000, September). Private higher education in developing countries: Private interest ... public good. Paper read at the New Zealand Association of Private Education Providers (NZAPEP) Cooperative Change in Tertiary Education Conference, Wellington, NZ.

Leibbrandt, M., \& Mlatsheni, C. (2004, October). Youth in Sub-Saharan labour markets. Paper presented at the Development Policy Research Unit (DPRU)/Trade and Industrial Policy Strategies (TIPS) Conference. Somerset West, South Africa.
Levy, D. (2003). Profits and practicality: How South Africa epitomises the global surge in commercial private higher education. WP No. 2 February 2003 Program for Research on Private Higher Education (PROPHE) Education Administration \& Policy Studies University at Albany, State University of New York. Retrieved on February IO, 20I4, http://www.albany.edu/dept/eaps/prophe/publication/ paper/PROPHEWPO2_files/PROPHEWPO2_Profits.htm

Lewin, K. (2007). Improving access, equity, and transitions in education: Creating a research agenda. Consortium for Research on Educational Access, Transitions and Equity (CREATE) Pathways to Access. Research Monograph No I. Brighton, UK: University of Sussex Center for International Education.

Psacharopoulos, G. (I973). Returns to education: An international comparison. San Francisco, California, USA: Elsevier-Jossey Bass.

Psacharopoulos, G. (I98I). Returns to education: An updated international comparison. Comparative Education, 17(3), 32I-4I.

Psacharopoulos, G. (1982). The economics of higher education in developing countries. Comparative Education Review, 26(2): 139-59.

Psacharopolous, G., \& Patrinos, H. (2002). Returns to investment in education: A further update. World Bank Policy Research Working Paper 288I. Washington, DC: World Bank.

UIS (UNESCO Institute for Statistics). (20I0). Trends in tertiary education: Sub-Saharan Africa. UIS Fact Sheet, December, No. Io. Montreal: UNESCO Institute for Statistics.

Walenkamp, J., \& Boeren, A. (2007). What donors should do. Development a Cooperation, No. 9. Cited by Sian Lewis (Funding for higher education: Facts and figures) http://www.scidev.net/global/ migration/feature/funding-for-higher-education-facts-and-figures. $\mathrm{html}$ ? stay=full. The original reference is no longer available on the internet.

World Bank. (2002). Constructing knowledge societies: New challenges for tertiary education. Washington, DC: World Bank.

World Bank. (2005). Equity and development. World Development Report. Washington, DC: World Bank.

World Bank. (2010). Financing higher education in Africa. Washington, DC: World Bank.

World Bank. (20II, February). Education in Ghana: Improving equity, efficiency, and accountability of education service delivery. Report No. 59755-GH. Washington, DC: World Bank. 